\title{
The Jobless Recovery: Does It Signal a New Era of Productivity-led Growth?
}

BY FAR THE MOST WIDELY NOTED and puzzling aspect of the current economic recovery is its failure to create jobs. While payroll employment in seven previous recessions increased a full 7 percent in the first twenty-three months following the NBER business cycle trough, such employment increased by only 0.8 percent-just over one-tenth as much-from March 1991 to March 1993. ${ }^{1}$ Part of the explanation of negligible job growth lies in the recovery's relatively slow pace of output growth, which has been little more than one-third the usual postwar pace. $^{2}$

The remaining part of the job puzzle stems from the ebullient performance of productivity - that is, output per hour in the nonfarm business sector-which registered a growth rate of 3.2 percent in the four quarters ending in 1992:4, the most rapid rate recorded in any similar period

This research has been supported by the National Science Foundation. Dan Aaronson provided able research assistance, and Sandy Choi typed the tables with admirable speed and accuracy. Martin N. Baily, Michael Harper, Jack E. Triplett, and participants in a NBER Productivity Research Meeting and at an American Economics Association session on productivity provided helpful comments on earlier drafts.

1. The seven previous troughs are those from 1949 to 1982, with the exception of July, 1980. See Ritter (1993).

2. The annual growth rate of nonfarm business output (Bureau of Labor Statistics measure) was 2.42 percent at an annual rate in the first seven quarters of the 1991-93 recovery, only 39 percent of the 6.25 percent annual rate achieved in the first seven quarters of seven previous postwar recoveries (including all but the abortive 1980-81 recovery). 
for more than sixteen years. ${ }^{3}$ The share of output growth accounted for by productivity growth in the current recovery is 112 percent, far exceeding the 47 percent average of the previous postwar recoveries at the same stage.$^{4}$ For any given pace of output growth, more rapid productivity growth by definition implies less rapid growth in labor input. This suggests that the recent revival in productivity growth may be the key to understanding the puzzling absence of job creation in the recovery.

Productivity-led growth is nothing but good news. In the two decades ending in mid-1992, the nonfarm business sector registered an average annual productivity growth rate of less than 1 percent: 0.85 percent, to be exact. ${ }^{5}$ Imagine the benefits to the economy if the recent good news on productivity were to imply, as some have suggested, a doubling in productivity growth to a rate of 1.7 percent over the next decade. ${ }^{6}$ For any given path of labor input, nonfarm private business output in the year 2003 would be almost 9 percent larger-some $\$ 450$ billion moreallowing that much more private and/or public spending. Productivityled growth does not imply a jobless recovery in anything but the shortest run. Instead, any beneficial shock to productivity growth sets the stage for lower inflation that enables policymakers to stimulate output growth sufficiently to create the same number of jobs that would have occurred in the absence of the shock. If the jobless character of the 1991-93 recovery indeed has been caused by a benign productivity shock, then its jobless character implies that there has been too little stimulus to output growth, not that a productivity surge must necessarily rob the nation of jobs.

3. The 3.2 percent four-quarter rate achieved in 1992:4 was most recently exceeded by a rate of 4.8 percent in 1976:1. The highest rate achieved in the previous business cycle was 4.8 percent in 1973:1.

4. In the first seven quarters of the recent recovery, the annual growth rates of nonfarm business output and output per hour were 2.42 and 2.71 percent, respectively. The unweighted averages of seven previous postwar recoveries were 6.25 and 2.94 percent, respectively.

5. This is the annual growth rate between 1972:2 and 1992:2. When the most recent two quarters are included, the growth rate rises to 0.92 . The quarter chosen for this comparison, 1972:2, is judged to be a "cyclically neutral" quarter, as discussed in table 3 . As I discuss below, weighting problems bias downward the measured rate of productivity growth before 1987 .

6. Stephen S. Roach of Morgan Stanley predicts that nonfarm business productivity will grow at the rate of 1.7 to 1.8 percent per year during the 1990s. See Sylvia Nasar, "U.S. Output per Worker Is Growing: Recent Data Show Productivity Is Up," New York Times, November 27, 1992, p. D9. 
Alternative Interpretations: A New Era versus the Usual Cyclical Rebound?

This paper takes a skeptical view of the widely held belief that a new era of faster productivity growth is at hand. Weighed against the innumerable tales of corporate restructuring and downsizing is a much more pessimistic story told by the official data on productivity growth over the last few years.

THE CASE FOR A NEW ERA. The universal theme of recent commentaries is that this recovery is unique in the continuing onslaught of permanent job terminations, mainly by large corporations, and the apparent refusal of employers (large and small) to hire new employees. The Economist prompted the title of this paper when it argued, "America is enjoying its first productivity-led recovery for many decades." ${ }^{7}$ Secretary of Labor Robert Reich has expressed concern about "job gridlock." 8 Lawrence Mishel and Jared Bernstein have highlighted the fact that roughly three-quarters of the rise in unemployment in the early 1990s has been due to permanent job loss, so that the absolute magnitude of permanent job loss has been as great in this relatively mild recession as in the much deeper 1981-82 recession. ${ }^{9}$ While a productivity surge during the recovery is normal, Stephen S. Roach has argued "there is reason to believe that what's happening this time is different ... a job shakeout that is an inevitable byproduct of market globalization." 10 The Wall Street Journal has heralded an "age of angst" and announced that a "workplace revolution boosts productivity at [the] cost of job security." 11

A particular aspect of the recent recovery has been the disproportionate share in corporate layoffs of white-collar workers and of workers in the service sector, in contrast to the decimation of manufacturing employment and of the Rust Belt that characterized employment adjustments a decade ago. As Roach has argued, "Corporate America can no

7. "America the Super-fit," Economist, February 13, 1993, p. 67.

8. See "Biggest Rise Since " 72 for Productivity," Chicago Tribune, March 10, 1993, p. 3.

9. See Mishel and Bernstein (1992, p. 5).

10. Stephen S. Roach as paraphrased by Forbes. See "What's Ahead for Business," Forbes, March 1, 1993, p. 37.

11. G. Pascal Zachary and Bob Ortega, "Age of Angst: Workplace Revolution Boosts Productivity at Cost of Job Security," Wall Street Journal, March 10, 1993, p. A1. 
longer afford to subsidize the bloat of unproductive workers . . These efficiency breakthroughs have taken a steep toll on an entirely new class of victims-white-collar workers. White-collar unemployment now exceeds blue-collar joblessness by 200,000 workers, the first such gap on record." 12

THE OPPOSING VIEW: A NORMAL CYCLICAL REBOUND. Journalistic accounts focus on corporate downsizing of particular firms having unusual problems, such as IBM and Sears, and leave out the much less dramatic humdrum everyday business of gains in sales and employment by their competitors. As American Enterprise Institute economist Marvin Kosters has noted, "Sears announces job cutbacks. Ever see any references to Wal-Mart hiring anyone? I never heard of Microsoft ever hiring a worker, but they must have." 13

Moving from anecdotal evidence to the hard facts, journalistic accounts have highlighted only the heady numbers of recent productivity performance over the past four quarters without lingering on the dismal performance of the four years before that. In contrast to the long-run growth rate since 1972 of slightly less than 1 percent per year, the annual growth rate of nonfarm private productivity recorded for the four years ending in 1991:4 was virtually zero: 0.11 percent per year, to be precise. The big boom of 3.2 percent for the following four quarters only brought the rate for the past five years up to 0.74 percent, still below the 1972-87 average.

It is always tempting to proclaim a new era on the basis of a few months or quarters of macroeconomic data. Yet the productivity record viewed over any period longer than the last four quarters displays faint support for a new era. Because the actual rate of productivity growth achieved through the end of 1992 over the past five years is below, not above, the lamentable pace of 1972-87, those claiming that the trend rate has increased must be assuming that the actual level of productivity in 1992:4 was well below the new rapidly growing trend. Any assessment of the new era approach requires a model of the cyclical deviation of productivity from trend at each stage of the business cycle. What is a plausible estimate of the deviation of actual productivity below its trend at

12. Stephen S. Roach, "The New Majority: White-Collar Jobless," New York Times, March 14, p. E17.

13. Quoted in Jerry Flint, "Keep a Resume on the Floppy, But Don't Panic," Forbes, April 26, p. 69. 
this stage of the business cycle? The econometric analysis of this paper provides an answer to this and other related questions.

\section{Separating Trend and Cycle}

At least since the early 1960s, when Thor Hultgren ${ }^{14}$ and Arthur M. Okun $^{15}$ published their analyses, macroeconomists have known that productivity exhibits procyclical fluctuations. Any evaluation of the long-term productivity performance of the economy requires that the underlying trend be unscrambled from quarter-to-quarter cyclical movements. This task cannot be achieved simply by measuring productivity growth between successive NBER-demarcated cyclical peaks or between successive troughs, for at least three reasons. First, productivity is a leading indicator and reaches its peak at a different point in the cycle from the official National Bureau of Economic Research (NBER) peak: Second, cycles are of different durations and amplitudes, and so the relationship of the productivity peak to the NBER peak is variable, rather than fixed. Third, the last stage of the business cycle expansion is marked by a regular phenomenon that I have previously called the endof-expansion effect, the unusually slow productivity growth that seems to occur in the last year or two before the NBER peak. ${ }^{16}$

The importance of separating trend from cycle is motivated by many considerations in addition to the natural interest in whether the economy's long-term productivity performance has gotten better or worse. First, any evaluation of past economic policies, such as the effect of supply-side tax cuts or R\&D tax credits, requires a measure of their effect on cyclically adjusted productivity growth. Second, assessments of the performance of political eras, such as the Eisenhower era or the ReaganBush era, must refer to productivity purged of purely cyclical effects. Finally, estimates of future growth in potential output (that is, trend productivity plus trend hours) are needed to project the federal budget, the likely path of unemployment, and even the inflationary consequences of alternative monetary policies.

This paper's basic purpose is to develop a method for determining what information about the underlying trend is provided by the latest

14. Hultgren (1960).

15. Okun (1962).

16. Gordon (1979). 
data on actual productivity movements. The second part begins with data issues, which play a surprisingly important role in assessing the validity of the interpretation of a new era. The third part then assesses two alternative detrending techniques and describes the data on actual and trend movements in average labor productivity (ALP) and multifactor productivity (MFP). The fourth part sets out the specification of a timeseries regression equation that identifies the cyclical parameters and also presents the estimated equations. The fifth part then provides alternative measures of the underlying trend for 1987-92 that result in the best fit to the cyclical adjustment model. The section also computes forecasts of productivity growth over the 1993-94 period. The sixth and final part presents conclusions.

All the empirical analysis is carried out for three sectors-nonfarm business, manufacturing, and the nonfarm nonmanufacturing business sector (NFNM). While historical growth rates are displayed for both average labor productivity and multifactor productivity, the econometric analysis concentrates entirely on average labor productivity.

\section{Data and Detrending}

There are three official sources of data on productivity for the U.S. economy. Annual data on gross product originating (that is, value added) and hours worked are part of the National Income and Product Accounts (NIPA). ${ }^{17}$ Unfortunately, the NIPA data for output by industry are not currently available after 1989. The Bureau of Labor Statistics (BLS) provides data on gross output, employment, and (in some cases) hours worked for a long list of industries in both the manufacturing and nonmanufacturing sectors; these are available through 1990 (or, in some cases, 1991). But the BLS provides no aggregates corresponding to its industry-by-industry measures. Both the NIPA and BLS industry measures share a defect; they are available only annually and thus are not suitable for a study of high-frequency time-series dynamics.

17. Hours worked are provided for major industrial sectors at roughly the one-digit level (NIPA table 6.11), while output (table 6.2) and persons engaged (table 6.10b) are provided for a much longer list of two-digit industries. Table numbers refer to those using 1982 as the base year. 
Thus by default this study uses the third data source based on Productivity and Costs, the BLS quarterly series on output and hours worked in the private nonfarm economy and in manufacturing. The BLS also publishes annual series for these two sectors on capital input and capital's income share-required ingredients in computing its annual measures of MFP. Here I interpolate the capital input and income share data from the annual to the quarterly frequency (using overlapping four-quarter moving averages) in order to compute a quarterly series on MFP for each sector.

While the BLS does not publish series for the NFNM sector, these can be calculated as a residual. I calculate NFNM by multiplying the BLS index numbers for the aggregate series and for manufacturing by the Bureau of Economic Analysis (BEA) absolute levels of output, hours, and capital input in 1982 . The NFNM totals are then obtained by subtraction and are converted back to index numbers.

The underlying source for the BLS output measure in the private nonfarm sector is the NIPA quarterly series on GDP, minus general government, farm output, output of nonprofit institutions, output of paid employees of private households, the rental value of owner-occupied dwellings, and the statistical discrepancy. The hours data are obtained from the monthly payroll employment survey, combined with hours per employee from the BLS hours at work survey. Adjustments are made to exclude from labor input the same sectors that are subtracted from GDP in obtaining the output series. The annual capital input and capital share are recomputed by the BLS from BEA data.

To obtain quarterly data on manufacturing output, the BLS takes quarterly movements in the Federal Reserve Index of Industrial Production (IIP) and adjusts these to the annual manufacturing output levels in the NIPA. Because the NIPA do not yet include annual series on manufacturing output for the period after 1989, the BLS extrapolates the NIPA output series with the IIP.

\section{Data Issues}

By far the most important data issue for the results of this paper is the so-called base-year weighting bias. This bias understates the growth rate of productivity before 1987 . This substantially raises the hurdle to be leaped by those who would proclaim a new era of productivity growth, 
because the economy's productivity performance during the slowdown from 1972 to 1987 was substantially better than is indicated by the currently published official data.

THE BASE-YEAR WEIGHTING BIAS. The BLS output data used in this paper for the aggregate economy (that is, the nonfarm business sector) reflect the rebasing of output deflators from 1982 to 1987 prices. While the BEA has not yet published manufacturing output data for the 1987 base year, it has prepared for the BLS productivity program an unpublished series of revised 1987-weighted manufacturing output data covering $1977-89 .{ }^{18}$ Thus the BLS output data used in this paper provide a consistent treatment of the aggregate economy and of manufacturing, which allows nonfarm nonmanufacturing output to be extracted as a residual.

However, as is well known, output measures based on the fixed weights of a single year lead to a systematic bias: for products such as computers with a rapidly declining relative price, the share of output in higher aggregates (such as manufacturing, producers' durable equipment, and GDP) will be exaggerated in each year after the base year and understated in each year before the base year. The base-year bias correspondingly causes the annual growth rate of output and of productivity to be understated in each year prior to the base year and overstated in each year after the base year.

Table 1 summarizes what is known about the base-year bias in the BEA output series for the aggregate economy for the 1959-90 period and for manufacturing during the $1977-87$ period. Bias is measured here by the difference between the data based on 1987 weights and on data calculated using BEA's benchmark-year series. The latter is based on a geometric mean of indexes from succeeding BEA benchmark years, which are five years apart. ${ }^{19} \mathrm{I}$ have supplemented published BEA estimates of the base-year bias by providing an estimate of the manufacturing bias for 1972-77, derived the implied base-year bias for nonfarm nonmanufacturing for 1972-87, and then applied these bias figures to the published

18. I am grateful to Michael Harper for providing me with a BLS press release dated March 26, 1992, that describes the special BEA series on manufacturing output used by the BLS productivity program.

19. See Young (1992) for more detailed information about fixed-weight and benchmark-years indexes. 
Table 1. Effect of Alternative Weighting Systems on Aggregate and Sectoral Productivity, 1959-90

Percent per year

\begin{tabular}{|c|c|c|c|c|c|c|}
\hline \multirow[b]{2}{*}{ Sector } & \multirow[b]{2}{*}{ Period } & & \multicolumn{2}{|c|}{ Output per hour } \\
\hline & & $\begin{array}{c}\text { Fixed } \\
1987 \\
\text { weights } \\
\text { index }\end{array}$ & $\begin{array}{l}\text { Bench- } \\
\text { mark- } \\
\text { years } \\
\text { index }\end{array}$ & $\begin{array}{c}\text { Difference } \\
\text { (bias) }\end{array}$ & $\begin{array}{c}\text { Fixed } \\
1987 \\
\text { weights } \\
\text { index }\end{array}$ & $\begin{array}{c}\text { Implied } \\
\text { bench- } \\
\text { mark- } \\
\text { years } \\
\text { index }^{\mathrm{a}}\end{array}$ \\
\hline \multirow{4}{*}{$\begin{array}{l}\text { Aggregate } \\
\text { economy }\end{array}$} & $1959-72$ & 3.7 & 4.1 & 0.4 & 2.4 & 2.8 \\
\hline & $1972-77$ & 2.6 & 2.9 & 0.3 & 1.3 & 1.6 \\
\hline & $1977-87$ & 2.6 & 2.9 & 0.3 & 0.7 & 1.0 \\
\hline & $1987-90$ & 2.5 & 2.4 & -0.1 & 0.0 & -0.1 \\
\hline \multirow[t]{2}{*}{ Manufacturing } & $1972-77$ & 2.8 & $3.8^{\mathrm{c}}$ & $1.0^{c}$ & 2.5 & 3.5 \\
\hline & $1977-87$ & 1.6 & 2.6 & 1.0 & 1.8 & 2.8 \\
\hline \multirow[t]{2}{*}{ Nonmanufacturing ${ }^{b}$} & $1972-77$ & 2.9 & $2.8^{\mathrm{c}}$ & $-0.1^{\mathrm{c}}$ & 0.8 & 0.7 \\
\hline & $1977-87$ & 3.1 & 3.2 & 0.1 & 0.2 & 0.3 \\
\hline
\end{tabular}

Source: Author's calculations using the following sources. Aggregate economy refers to real GDP, from Young (1992, table A, p. 36). Manufacturing for 1972-77 is estimated as described in note b below. Manufacturing for 197787 is also from Young (1992, exhibit 1, p. 34). The 1982 values of manufacturing real GDP are obtained from Survey of Current Business (January 1991, table 6, p. 34); values for other years are obtained by multiplying the BLS output series (expressed as an index with $1982=1.0$ ) by the 1982 values. Output per hour for manufacturing was obtained from Bureau of Labor Statistics, Productivity and Costs, various issues, as described in the text. Hours data for manufacturing are from Survey of Current Business, table 6.11, various issues, using 1982 as the base year.

a. The implied benchmark-years index for productivity is the sum of the fixed 1987 weights index for output per hour plus the bias in output between the fixed weight and benchmark years indexes.

b. Nonmanufacturing output is aggregate real GDP minus manufacturing real GDP.

c. Manufacturing output data for 1972-77 have not been published with 1987 fixed weights and are available only with 1982 fixed weights. The problem is to estimate the base-year bias for 1972-77 with 1982 fixed weights. This is the same number of years prior to the base year as 1977-82 with 1987 fixed weights, for which Young (1992, exhibit 1, p. 34) provides an estimated base-year bias of 1.4 percentage points per year. To be conservative, and because computers are less important in earlier years, these 1.4 percentage points are reduced to the 1.0 percentage point bias shown in the third output column labeled "Difference" for manufacturing during 1972-77.

growth rates of the BLS series on output per hour. For the aggregate economy, productivity growth is understated by about 0.3 percent per year during 1959-87 and is overstated by 0.1 percent per year during 1987-90. Manufacturing productivity growth is overstated during 197287 by a much larger 1.0 percent per year, while there appears to be little if any bias in nonmanufacturing productivity growth.

While no estimate is available of the base-year bias for manufacturing after 1987, one would assume that it might be relatively large for 198792, the first five years after the base year. The best guess that might pin down the approximate size of the bias comes from the BEA's estimate that with 1982 weights, the growth in manufacturing output for 1982-87 
is overstated by 0.8 percent per year..$^{20}$ However, a mitigating factor is that the BEA has not calculated manufacturing output after 1989, and instead the BLS extrapolates the 1989-92 values using the IIP, which is not subject to the same type of base-year bias.

IIP USE OF EMPLOYMENT DATA. Monthly changes in the IIP are partly based on employment data. To the extent that productivity is procyclical, output measures based on the IIP will understate the degree of cyclicality. Assuming that quarterly fluctuations in GDP are accurate, the use of IIP to create the manufacturing output series leads to an understatement of the procyclicality in manufacturing productivity and the opposite bias for NFNM productivity, because the latter is calculated as a residual. More generally, the calculation of NFNM data as a residual will lead to measurement errors that go in the opposite direction from errors in the manufacturing data. However, because the NFNM sector is three times larger than the manufacturing sector in absolute size, any such measurement errors in percentage change data for NFNM will be one-third the size of the corresponding errors in manufacturing.

PAYROLL EMPLOYMENT VERSUS HOUSEHOLD EMPLOYMENT. As indicated in the introduction, payroll employment stagnated during the 1991-93 recovery, with growth between March 1991 and March 1993 of only 0.8 percent. This contrasts with growth of 1.5 percent-almost twice as fast-in civilian employment from the household survey. This contrast appears to be a normal feature of business cycles. ${ }^{21} \mathrm{~A}$ more convincing hint that the payroll employment numbers grow too slowly is provided by the discrepancy between the national total published by the BLS and the sum of estimates issued by individual states. By one estimate, this discrepancy could lead to a subsequent upward revision to payroll employment of as much as 0.7 percent. $^{22}$

20. Young (1992, exhibit 1, p. 34).

21. To assess the normal cyclical fluctuations in the ratio of civilian household to nonfarm payroll employment, this ratio was regressed in annual data for 1972-92 on a constant, a trend, one lagged value of the dependent variable, and the current and one lagged value of the unemployment gap (the actual unemployment rate minus my estimate of the natural unemployment rate). The residual for 1992 is close to zero and less than half of the standard error of the equation.

22. See Gene Koretz "New Numbers Are Brightening the Employment Outlook," Business Week, May 3, p. 22. Koretz reported that the growth from September 1991 to January 1993 of the national payroll employment estimate was 0.5 percent and the sum of the individual states estimate was 1.1 percent. 


\section{Detrending}

The basic question addressed by this paper is whether the underlying trend of average labor productivity has accelerated in recent years. Much recent empirical work in macroeconomics uses the Hodrick-Prescott filter, which allows the trend to move continuously. ${ }^{23}$ The trend that emerges from the H-P filter calculation depends on the user's choice of a smoothness parameter. At one extreme, the choice of a parameter of zero yields a trend that exactly tracks every value of the series being detrended. At the other extreme, a parameter of infinity yields a single straight loglinear trend. Between zero and infinity, a relatively low value for the smoothness parameter creates a trend series that bends frequently in response to changes in the actual series and hence implies relatively small deviations from trend; a high parameter value creates a relatively smooth trend and relatively larger deviations from trend. The parameter endorsed by Hodrick and Prescott is a relatively low value $(1,600)$ that implies implausibly large accelerations and decelerations of the trend within each business cycle. ${ }^{24}$

Table 2 compares actual growth rates of average labor productivity for three periods-1972-87, 1987-90, and 1990-92-with computed H-P trends for ALP, using five alternative values of the smoothness parameter. This comparison is displayed from the top to the bottom of table 2 for the three sectors (nonfarm business, manufacturing, and NFNM). As would be expected, the coherence of the H-P trend with the growth rates of the actual values is greatest for the lowest numerical

23. Hodrick and Prescott (1981).

24. Hodrick and Prescott (1981, pp. 5-8) provide a justification of a value for their smoothness parameter of 1,600 , and this has been used in their subsequent work (such as Prescott, 1986) and the work of most other H-P users. Yet this justification is based entirely on a subjective statement: "Our prior view is that a five percent cyclical component is moderately large as is a one-eighth of one percent change in the growth rate in a quarter. This led us to select $\sqrt{\lambda}=5 /(1 / 8)=40$ or $\lambda=1,600$ as a value for the smoothing parameter." To interpret their prior, consider the Great Depression of 1929-33 (when real GDP fell 34 percent below a 2.5 percent per year log-linear trend extending from 1928 to 1948). One can multiply their example of $5 /(1 / 8)$ by 5 , for a cyclical component of 25 percent and a reduction in the growth trend of $5 / 8$ percent per quarter or 2.5 percent per year. Thus in their interpretation, the computed trend had zero growth between 1929 and 1933 despite continued growth in the working-age population and in the productivity that would have been observed at a constant unemployment rate. 
Table 2. Trend Growth Rates of Labor Productivity Using Hodrick-Prescott Filter

\begin{tabular}{llcrc}
\hline Sector & Smoothness parameter & $1972: 2-1987: 3$ & $1987: 3-1990: 3$ & $1990: 3-1992: 4$ \\
\hline Nonfarm business & None (actual values) & 0.99 & -0.23 & 1.95 \\
& 400 & 0.96 & 0.21 & 1.01 \\
& 1,600 & 0.95 & 0.45 & 0.66 \\
& 6,400 & 0.93 & 0.62 & 0.59 \\
& 25,600 & 0.93 & 0.68 & 0.62 \\
Manufacturing & 102,400 & 0.97 & 0.66 & 0.60 \\
& None (actual values) & 2.13 & 2.49 & 2.31 \\
& 400 & 2.07 & 2.37 & 2.34 \\
& 1,600 & 2.07 & 2.53 & 2.31 \\
& 6,400 & 2.04 & 2.66 & 2.47 \\
Nonfarm & 25,600 & 2.05 & 2.60 & 2.49 \\
nonmanufacturing & 102,400 & 2.11 & 2.36 & 2.28 \\
business & None (actual values) & 0.48 & -1.10 & 1.86 \\
& 400 & 0.23 & -0.35 & 0.60 \\
& 1,600 & 0.20 & -0.10 & 0.20 \\
& 6,400 & 0.16 & 0.06 & 0.11 \\
& 25,600 & 0.17 & 0.09 & 0.10 \\
& 102,400 & 0.24 & 0.04 & 0.04 \\
\hline
\end{tabular}

Source: Based on author's calculations using five alternative values of a smoothness parameter for the HodrickPrescott filter as described in the text. Actual data are taken from Bureau of Labor Statistics, Productivity and Costs, various issues.

value of the smoothness parameter. As the smoothness parameter increases, the computed trend is equalized across the three subperiods. Despite these patterns, the choice of the smoothness parameter does not appear to make much difference; for the nonfarm business sector in the top section of the table, any parameter of 1,600 or more yields a trend for $1990-92$ of only 0.6 percent at most-well below the 0.99 percent actual rate recorded from 1972-87. In the NFNM sector, the H-P trends of around 0.1 percent per year are also well below the actual 1972-87 rate of 0.48 percent. Only in manufacturing is there a post-1987 acceleration, and here the actual value grows so smoothly that all the alternative H-P trends grow at a rate roughly similar to that of the actual value.

Figure 1 displays one of the computed H-P trends for the nonfarm business sector (this series assumes a smoothness parameter of 25,600 ) and compares it with the actual values over the 1972-92 period. Note that the actual value in late 1992 rises well above the H-P trend, in contrast to the 1983-84 recovery when the actual value did not significantly exceed the trend. This contrast suggests that the computed H-P trends for the recent period may grow too slowly. But figure 1 also illustrates a 
Figure 1. Labor Productivity and H-P Trend for Nonfarm Business ${ }^{\text {a }}$

Index, $1982=100$

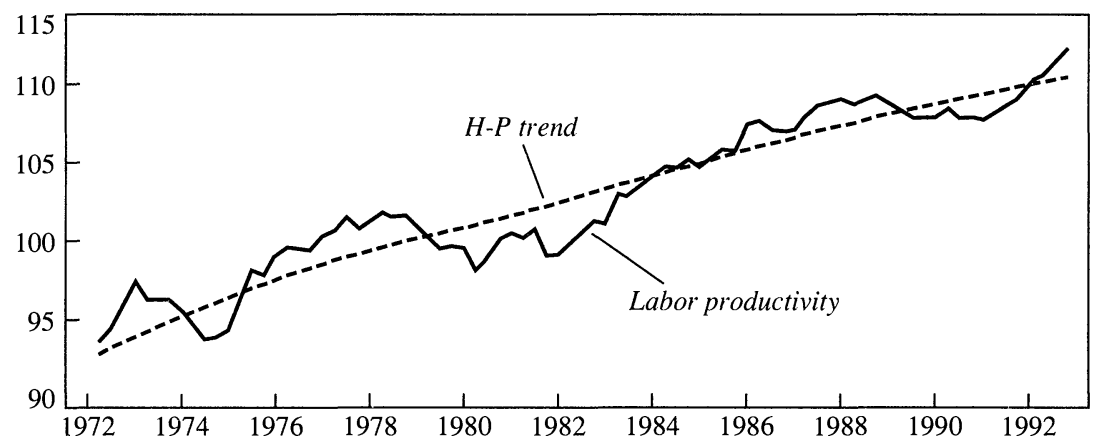

Source: Author's calculations based on Bureau of Labor Statistics, Productivity and Costs, various issues. a. The H-P (Hodrick-Prescott) smoothness parameter is set to 25,600 .

basic dilemma in assessing the recent episode. Because actual productivity growth was so slow over the 1987-91 period, almost any trend line must interpret much or all of the 1992 acceleration as simply a catchup, rather than representing the beginning of a new faster trend. The 1992 acceleration has not yet lasted long enough to provide reliable evidence that the trend has accelerated relative to the 1972-87 growth rate of about 1 percent per year (as measured by the official 1987-fixed-weight data, or 1.3 percent with the alternative benchmark-weighted data).

The alternative detrending technique used in the rest of this paper is to draw piecewise loglinear trends through selected benchmark quarters. This technique has the advantage that it can use outside information on variables other than the one being detrended-for example, such variables as unemployment and the capacity utilization rate-to select benchmark quarters having similar cyclical characteristics. ${ }^{25} \mathrm{~A}$ further advantage of piecewise trends is that there is one trend per business cycle, thus achieving a clean break between the business cycle fre-

25. In contrast, the univariate H-P technique ignores outside information. For instance, using the same smoothness parameter as that recommended by Hodrick and Prescott $(1,600)$, Finn E. Kydland and Edward C. Prescott $(1990$, chart 2, p. 9) illustrate the log levels of actual and trend real GNP and show that almost the entire boom of the 1960s is interpreted as an acceleration of the trend, rather than a deviation of actual above the trend. This ignores outside information, such as the fact the that the unemployment rate in the mid-1960s was unusually low and that the capacity utilization rate was unusually high. 
Figure 2. Productivity in Nonfarm Business ${ }^{a}$

Index, $1972: 2=100$

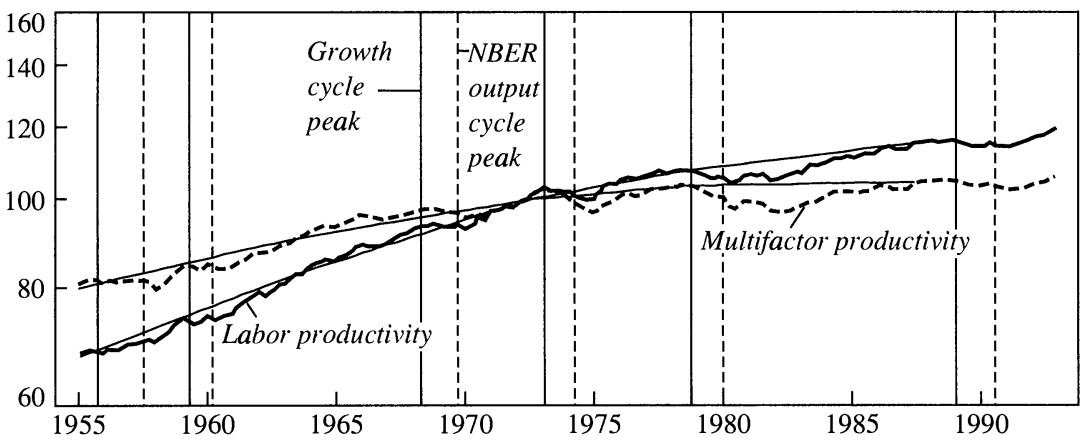

Source: Author's calculations based on Bureau of Labor Statistics, Productivity and Costs, various issues. See the text for more details on source information and for an explanation of the author's methodology.

a. Vertical bars designate end-of-expansion intervals. The solid line represents the growth cycle peak when output reaches its highest level relative to trend or potential output. The dashed line represents the NBER-dated output cycle peak, except for the line for 1974:2, when the NBER peak was dated as occurring in 1973:4.

quency represented by deviations from trend and the lower frequency changes in the trend from one business cycle to the next.

The business cycle in productivity differs from that in output. Figure 2 shows two measures of productivity and the dating of the expansion effects. Note that by this dating, productivity leads the output cycle, which is marked by the dashed vertical lines that identify NBER peaks. Productivity tends to reach its peak relative to trend when output is growing most rapidly. Further, productivity tends to perform poorly at the end of expansions. These observations suggest that benchmark quarters should be chosen by three criteria: to maintain roughly the same level of utilization of resources across cycles; to choose points at which the growth characteristics of output are roughly similar; and to exclude end-of-expansion periods. Six benchmark quarters that meet these criteria are displayed in table 3. Note that I exclude the short business cycles containing the incomplete recoveries of 1958-59 and 1980-81.

For the remaining six cycles, I choose quarters in which the unemployment rate was roughly equal to the natural rate identified in my previous research on inflation. ${ }^{26}$ Two such quarters occur in each cycle: one when unemployment is falling and another when unemployment is ris-

26. For example, see Gordon (1982). 
Table 3. Selected Variables in Benchmark Quarters

\begin{tabular}{ccccc}
\hline $\begin{array}{c}\text { Business } \\
\text { cycle } \\
\text { (peak to } \\
\text { peak) }\end{array}$ & $\begin{array}{c}\text { Quarter } \\
\text { selected }\end{array}$ & $\begin{array}{c}\text { Unemploy- } \\
\text { ment rate }\end{array}$ & $\begin{array}{c}\text { Capacity } \\
\text { utilization } \\
\text { rate }\end{array}$ & $\begin{array}{c}\text { Gordon } \\
\text { output } \\
\text { ratio }^{\mathrm{b}}\end{array}$ \\
\hline $1948-53$ & $1950: 2$ & 5.6 & 77.9 & 100.2 \\
$1953-57$ & $1954: 4$ & 5.3 & 79.7 & 100.1 \\
$1957-60$ & excluded & $\ldots$. & $\ldots$. & $\ldots$ \\
$1960-69$ & $1963: 3$ & 5.5 & 83.6 & 100.0 \\
$1969-73$ & $1972: 2$ & 5.7 & 82.0 & 101.1 \\
$1973-80$ & $1978: 3$ & 6.0 & 85.1 & 101.0 \\
$1980-81$ & excluded & $\ldots$. & $\ldots . .2$ & $\ldots$ \\
$1981-90$ & $1987: 3$ & 6.0 & 80.2 & 100.0 \\
\hline
\end{tabular}

Source: Unemployment rate is from Bureau of Labor Statistics, Employment and Earnings, various issues. Capacity utilization rate is from Federal Reserve Bulletin, various issues. Gordon output ratio is from Gordon (1993, appendix table A-2).

a. Criteria for selection are as follows: the unemployment rate, $U_{t}$, is as close as possible to the natural rate of unemployment as calculated in Gordon (1993, appendix table A-2); the unemployment rate is falling; and the endof-expansion effect dummy is nonoperative $\left(D_{k}=0\right.$ in equation 1 of the text).

b. The output ratio is the ratio of actual to natural output.

ing. I chose the former quarter; hence my benchmark quarters tend to be periods when output is rising relatively fast and thus productivity is relatively high. As a result, actual productivity is below trend on average over the postwar period. Table 3 also presents two other cyclical indicators, the Federal Reserve capacity utilization rate and the ratio of actual to natural output as calculated from my past research. Because unemployment is currently well above the natural rate of about 6 percent, there is no benchmark quarter to establish the trend for the period since 1987. Determination of the post- 1987 trend is the task of the final part of this paper.

\section{The Historical Behavior of Productivity}

Now equipped with a consistent set of benchmark quarters, one can examine plots of actual data and trends in the official data (ignoring for now the effects of the 1987 base-year weighting bias). The actual and trend values of ALP and MFP are shown for the three sectors in figures 2,3 , and 4 . The post-1987 trends are omitted, and for ALP, will be determined in the final part below. (The paper does not discuss the post-1987 trend of MFP.) The solid vertical lines in the figures mark off the end-ofexpansion periods highlighted in the regression analysis below. 
Figure 3. Productivity in Manufacturing a

Index, 1972:2 = 100

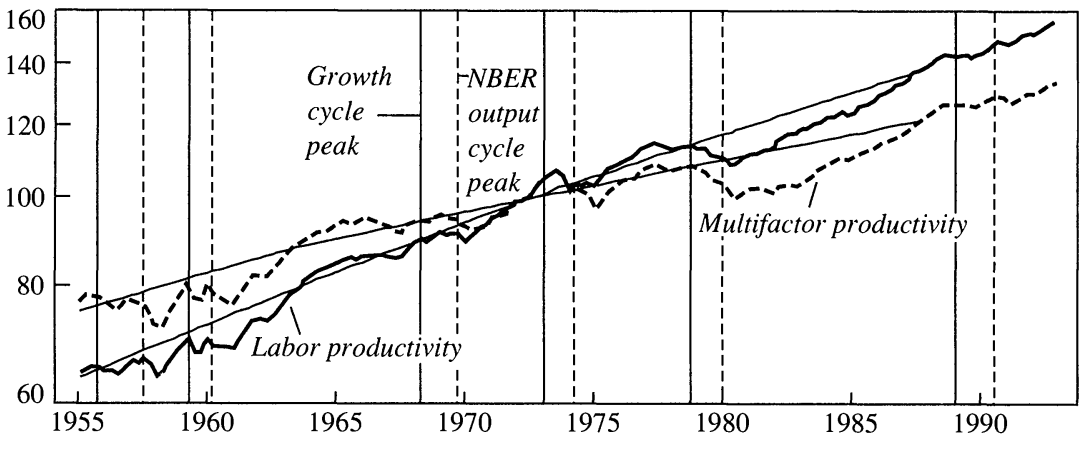

Source and notes: See figure 2.

Several facts about the nonfarm business sector stand out in figure 2 . The ALP trend decelerates after 1972 and decelerates further after 1978, indicating that the secular productivity slowdown worsened in the 1980s. The end-of-expansion periods marked by the solid vertical lines illustrate a phenomenon that appears to recur in each business cycle, with zero or negative ALP growth in 1959-60, 1968-69, 1973-74, 197880 , and 1989-90. MFP growth subtracts from output a weighted average of labor input and capital input growth. Because capital grew rapidly in the late 1960s, the slowdown in MFP growth began earlier than the slowdown in ALP growth.

Figure 3 for manufacturing contrasts sharply with figure 2; no slowdown appears to have occurred in the trend growth of ALP. The amplitude of cyclical fluctuations is greater, particularly during the period of weak growth in 1955-61, the 1973 bulge, and the 1977-80 decline. However, the cyclical fluctuations surrounding the latest recessions have been more moderate than in the total economy. The straight trend for ALP in manufacturing contrasts with the evidence for MFP, where a slowdown in growth seems to have occurred between 1967 and the early 1980 s, followed by a robust recovery. The rapid growth of ALP in manufacturing in the late 1980s and early 1990s is qualified by the base-year data bias, which affects manufacturing to a greater extent than the aggregate economy.

Because NFNM constitutes three-quarters of output in the private nonfarm sector, it is not surprising that figure 4 looks much like figure 2 , 
Figure 4. Productivity in Nonfarm Nonmanufacturing Business ${ }^{a}$

Index, 1972:2 = 100

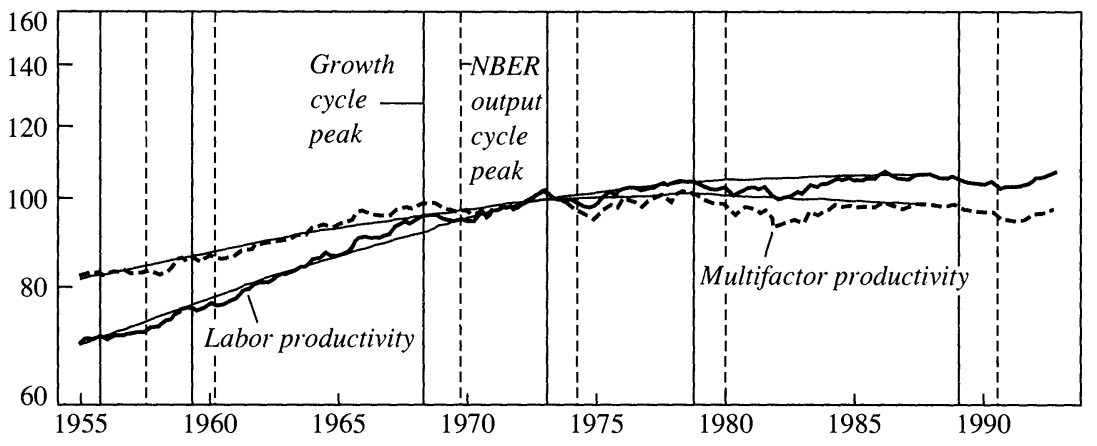

Source and notes: See figure 2 .

but with a sharper slowdown in trend ALP growth. Cycles in both ALP and MFP mimic those in figure 2.

Table 4 displays the annual average growth rates between benchmark quarters of output, hours, capital input, ALP, and MFP for all three sectors. Also shown in the right-hand column are growth rates from the most recent benchmark quarter, 1987:3, to the most recent quarter with available data, 1992:4. Among the important facts about the private nonfarm sector are the two-stage slowdown in ALP after 1972 and again after 1978, and the three-stage slowdown of MFP (with almost zero growth during 1978-87). After 1987, the growth rates of output, inputs, and ALP all decelerated, while MFP recovered a bit. ${ }^{27}$ Presumably, a good part of the deceleration in output and inputs was caused by the 1990-91 recession and slow pace of the 1991-93 recovery, but it remains to be seen how large the cyclical component in ALP is.

In manufacturing, the most striking facts are slow output growth since 1978, negative labor input growth since 1978, the acceleration in ALP growth after 1987 when compared to 1972-87, and the faster rate of MFP growth after 1987 than that achieved over the entire 1963-87 period. Corresponding to the relatively robust performance of manufacturing, particularly since 1987 , is the pathetic performance of the NFNM sector. Here ALP growth has been essentially zero since 1978, while

27. Capital input through 1991 is from the BLS, Productivity and Costs, various issues. Capital input for 1992 is based on a regression of capital input growth on the share of NIPA net investment in GDP from 1959 to 1991. 


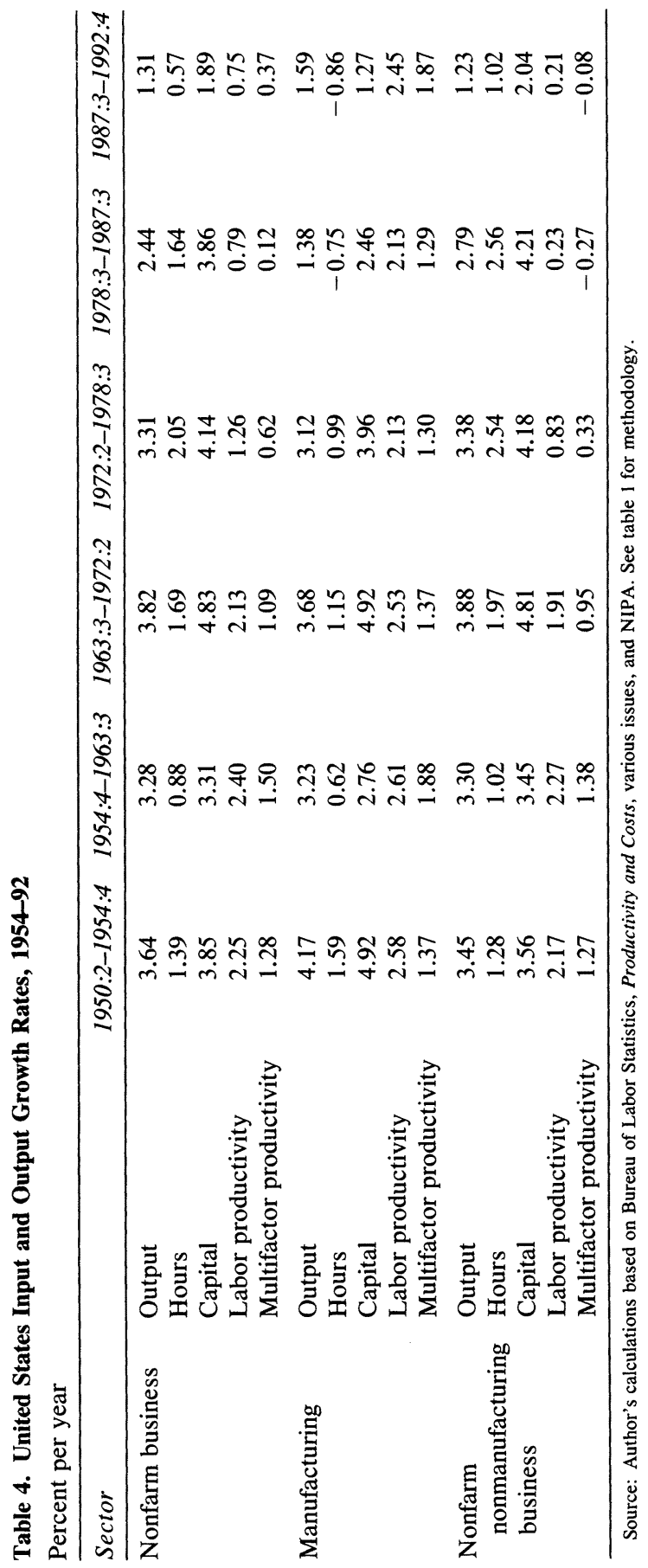


MFP growth has been negative since 1978, and the same three-stage deceleration in MFP growth occurred after 1963, 1972, and 1978. All comments are qualified by the previous remarks on base-year data bias.

\section{Econometric Specification and Estimation}

The rest of the paper is limited to an analysis of ALP; the same technique can be applied to MFP. To the extent that MFP is a more fundamental measure of underlying technical progress, my examination of ALP must be treated as an approximation. However, two problems arise with MFP that give ALP priority. First, several additional measurement errors enter into the calculation of MFP: errors in capital input and in capital's income share as a proxy for the true elasticity of output to capital. In addition, the maintained assumption of constant returns to scale may involve an error. Also, to develop predictions of future growth in potential output needed for forecasts of the federal budget, unemployment, and so on, an estimate of future MFP growth must be supplemented with predictions of growth in both labor and capital input. In contrast, in order to predict future growth in potential output, a forecast of future ALP growth needs to be joined only by a forecast of trend hours growth, which is less subject to error and does not require forecasts of investment behavior.

\section{Dynamic Specification and the End-of-Expansion Effect}

Following the 1974 work of Christopher Sims and my own 1979 work, ${ }^{28} \mathrm{I}$ estimate equations in which the dependent variable is the first difference of the log of hours relative to its trend $\left(\Delta h-\Delta h^{*}\right)$. This is regressed on a series of lagged dependent variable terms and on the first difference of deviations of the log of output from its trend $\left(\Delta q-\Delta q^{*}\right)$. The output deviation variable in principle can enter with leads, the current value, and lags. The lags can be interpreted as reflecting adjustment costs: that is, delays in hiring and firing. The use of leads was introduced by Sims in the context of his analysis of Granger causality between hours and output. ${ }^{29} \mathrm{~A}$ structural interpretation of leading output vari-

28. See Sims (1974) and Gordon (1979).

29. Sims (1974). 
ables is that the choice of labor input is based in part on a forecast of future changes in output.

Two additional variables are added to the traditional regression that relates first differences of hours deviations to first differences of output deviations. The first is an error-correction term. Recently, the concept of error correction has been linked to that of cointegration, which can be defined informally as the notion that a linear combination of two seriesfor example, the hours deviation and the output deviation-is stationary. ${ }^{30}$ When two such variables are cointegrated, a regression consisting entirely of differenced data will be misspecified, while a regression consisting entirely of level data will omit important constraints. The solution is to estimate a regression of the first difference of one variable on the first difference of the other, plus an error correction variable consisting of the lagged log ratio of one variable to the other. ${ }^{31}$

In my 1979 work, I identified a tendency for labor input to grow more rapidly than can be explained by output changes in the late stages of the business expansion. ${ }^{32}$ I dubbed this tendency toward overhiring the endof-expansion effect and argued that it was balanced by a tendency to underhire in the first two years or so after the end of the expansion. In this paper, I adopt a more systematic approach to defining and interpreting the EOE effect. According to the NBER definition, the expansion ends when real output (actually a collection of coincident indicators) reaches its absolute peak. This can be distinguished from the earlier peak of the growth cycle when output reaches its highest level relative to trend or potential output. The EOE period is defined here as the interval between the peak of the growth cycle and the peak of the NBER cycle; by definition, it is a period when output displays positive but subnormal growth. The overhiring that consistently occurs during the EOE period can be interpreted as resulting from individual firms incorrectly expecting that their output will keep rising at or above trend, while output for the aggregate economy turns out to grow more slowly than its trend rate.

The EOE effect is introduced into the regression equation through a set of six dummy variables. These are not 0,1 dummies; rather, they are

30. For the formal definition of stationarity and co-integration, see Engle and Granger (1987, pp. 252-53).

31. A complete taxonomy of the possible forms of dynamic specification in a bivariate model is presented in Hendry, Pagan, and Sargan (1984, pp. 1040-49).

32. Gordon (1979). 
in the form $1 / M,-1 / N$, where $M$ is the length in quarters of the period of the initial interval of excessive labor input growth and $N$ is the length of the subsequent correction. By forcing the sum of coefficients on each variable to equal zero, any overhiring in the initial phase is subsequently corrected. The length of the first period, $M$, is the number of quarters between the peak in the growth cycle and the peak of the NBER cycle. ${ }^{33}$ The timing and duration, $N$, of the subsequent correction period is determined by examining residuals in equations that omit the dummies entirely. ${ }^{34}$ The amplitude of the end-of-expansion effect is allowed to differ across business cycles by allowing the dummy variable for each episode to have its own separate coefficient. (I subsequently test whether these coefficients are significantly different from each other.)

Combining these explanatory variables, the basic equation to be estimated is

$$
\text { (1) } \begin{aligned}
\left(\Delta h-\Delta h^{*}\right)_{t}= & \mu+\sum_{i=k}^{L} \alpha_{i}\left(\Delta h-\Delta h^{*}\right)_{t-i}+\sum_{j=M}^{N} \beta_{j}\left(\Delta q-\Delta q^{*}\right)_{t-j} \\
& +\phi\left[(q-h)-\left(q^{*}-h^{*}\right)\right]_{t-1}+\sum_{k=1}^{6} \gamma_{k} D_{k}+\epsilon_{t},
\end{aligned}
$$

where $D_{k}=0$ in all quarters except the end-of-expansion and subsequent correction period, which are as follows:

$\begin{array}{ccccc}k & M & D_{k}=1 / M \text { during } & N & D_{k}=-1 / N \text { during } \\ 1 & 8 & 1955: 4-1957: 3 & 3 & 1957: 4-1958: 2 \\ 2 & 5 & 1959: 2-1960: 2 & 9 & 1960: 4-1962: 4 \\ 3 & 7 & 1968: 2-1969: 4 & 6 & 1970: 2-1971: 3 \\ 4 & 6 & 1973: 1-1974: 2 & 7 & 1974: 4-1976: 2 \\ 5 & 6 & 1978: 4-1980: 1 & 8 & 1981: 1-1982: 4 \\ 6 & 7 & 1989: 1-1990: 3 & 8 & 1991: 4-1993: 3\end{array}$

33. The peak of the growth cycle is defined by the ratio of real GDP to natural real GDP; the latter measure is taken from Gordon (1993, appendix table A-2). In the 1960s, peaks occurred in 1966:1 and 1968:2. I chose the latter. I chose the termination date of the fourth EOE episode to be 1974:2, rather than the NBER peak of 1973:4, because output remained at a plateau in the first half of 1974 , rather than declining as it normally does in a recession. (The level of real GDP in 1974:2 was only 0.3 percent below the annual average for the year 1973.)

34. The timing of the 1991-93 correction period is somewhat arbitrary. To avoid interpreting the 1992 productivity spurt entirely as the result of the EOE effect, the correction period is extended to 1993:3. But to prevent too sharp a jump in the growth of predicted hours from 1993 to 1994, the correction effect is allowed to taper off through 1993. (The correction part of the sixth dummy variable is defined as $1 / 6.5$ for $1991: 4-1992: 4 ; 0.75 / 6.5$ for 1993:1; 0.5/6.5 for 1993:2; and 0.25/6.5 for 1993:3). 
Here $\mu$ is the constant term; the $\alpha_{i}$ are the coefficients on the lagged dependent variable; the $\beta_{j}$ are the leading, current, and lagged coefficients on the change in the output deviation from trend; $\phi$ is the coefficient on the error-correction term; and the $\gamma_{k}$ are the coefficients on the end-ofexpansion dummies. The $\gamma_{k}$ coefficients indicate the cumulative amount of excess labor hired in a particular end-of-expansion episode, measured as a percent, and typical estimates below are in the range of 2.5 percent cumulative overhiring at the end of the expansion balanced by a cumulative -2.5 percent adjustment in hours during the subsequent recession and early stages of the recovery. ${ }^{35}$

\section{Estimation: Nonfarm Private Business}

Now that the trends for hours and output have been determined, along with the configuration of the end-of-expansion dummies, estimation of equation 1 is straightforward. Results for the nonfarm private business sector are displayed in table 5 . Changes in structure are tested by estimating over the entire sample period, 1954:4 to 1992:4, as well as for two subperiods broken roughly in half at 1972:4. The first three regressions display results for three variants that include the error-correction term and end-of-expansion dummies both separately and together. Prior testing not reported in the table determined that the current value and three lagged values of the output deviation variable are significant, but further lags are not; leading values (that Sims and I found to be significant $)^{36}$ lose their significance in the presence of either the error-correction term or end-of-expansion dummies. Thus in everything that follows, the line labeled output deviations refers to the sum of coefficients on lags $0-3$, and leading values are omitted.

The most important conclusions from the first three regressions are that the end-of-expansion dummies are highly significant, as is the errorcorrection parameter, $\phi$, by itself; however, in combination with the end-of-expansion dummies, the error-correction parameter becomes insignificant. The constant term, $\mu$, is always insignificant and is omitted in the last three columns. Hence my preferred specification is that shown in the third regression of table 5. Noting that the end-of-expan-

35. The dummy variable is defined as $1 / M$ and $-1 / N$ when I use annual data, and $4 / M$ and $-4 / N$ with quarterly data.

36. Sims (1974) and Gordon (1992). 
Table 5. Estimated Equations for Change in Nonfarm Business Hours Relative to Trend, 1954:4-1992:4

\begin{tabular}{|c|c|c|c|c|c|}
\hline Independent variable & $\begin{array}{l}1954: 4- \\
1992: 4\end{array}$ & $\begin{array}{c}1954: 4- \\
1992: 4\end{array}$ & $\begin{array}{l}1954: 4- \\
1992: 4\end{array}$ & $\begin{array}{c}1954: 4- \\
1972: 4\end{array}$ & $\begin{array}{l}1973: 1- \\
1992: 4\end{array}$ \\
\hline Constant & $\begin{array}{c}0.31 \\
(1.82)\end{array}$ & $\begin{array}{c}0.13 \\
(0.82)\end{array}$ & $\cdots$ & . . & $\cdots$ \\
\hline $\begin{array}{l}\text { Lagged dependent } \\
\quad\left(\Delta h-\Delta h^{*}\right)\end{array}$ & $\begin{array}{c}0.18 \\
(1.62)\end{array}$ & $\begin{array}{l}-0.29 \\
(-2.47)\end{array}$ & $\begin{array}{l}-0.32 \\
(-2.75)\end{array}$ & $\begin{array}{l}-0.40 \\
(-2.21)\end{array}$ & $\begin{array}{l}-0.25 \\
(-1.63)\end{array}$ \\
\hline $\begin{array}{l}\text { Output deviation } \\
\qquad\left(\Delta q-\Delta q^{*}\right)\end{array}$ & $\begin{array}{c}0.67 \\
(6.49)\end{array}$ & $\begin{array}{c}0.91 \\
(9.34)\end{array}$ & $\begin{array}{c}0.95 \\
(10.9)\end{array}$ & $\begin{array}{c}0.95 \\
(6.55)\end{array}$ & $\begin{array}{c}0.93 \\
(8.23)\end{array}$ \\
\hline Error-correction term & $\begin{array}{c}0.26 \\
(2.65)\end{array}$ & $\begin{array}{l}0.08 \\
(0.94)\end{array}$ & $\cdots$ & $\ldots$ & $\ldots$ \\
\hline \multicolumn{6}{|l|}{$\begin{array}{l}\text { End-of-expansion } \\
\text { dummies }\end{array}$} \\
\hline$\gamma_{1}(1955-58)$ & $\cdots$ & $\begin{array}{l}2.25 \\
(3.37)\end{array}$ & $\begin{array}{c}2.30 \\
(3.47)\end{array}$ & $\begin{array}{l}2.62 \\
(3.54)\end{array}$ & $\cdots$ \\
\hline$\gamma_{2}(1959-62)$ & $\cdots$ & $\begin{array}{l}1.95 \\
(2.65)\end{array}$ & $\begin{array}{l}1.97 \\
(2.69)\end{array}$ & $\begin{array}{l}2.01 \\
(2.63)\end{array}$ & $\cdots$ \\
\hline$\gamma_{3}(1968-71)$ & $\ldots$ & $\begin{array}{c}2.71 \\
(3.89)\end{array}$ & $\begin{array}{c}2.80 \\
(4.08)\end{array}$ & $\begin{array}{c}2.98 \\
(4.04)\end{array}$ & $\cdots$ \\
\hline$\gamma_{4}(1973-76)$ & $\cdots$ & $\begin{array}{c}3.24 \\
(4.37)\end{array}$ & $\begin{array}{l}3.35 \\
(4.58)\end{array}$ & $\cdots$ & $\begin{array}{c}3.13 \\
(3.86)\end{array}$ \\
\hline$\gamma_{5}(1978-82)$ & $\cdots$ & $\begin{array}{c}2.65 \\
(3.42)\end{array}$ & $\begin{array}{c}2.84 \\
(3.81)\end{array}$ & $\cdots$ & $\begin{array}{c}2.60 \\
(3.22)\end{array}$ \\
\hline$\gamma_{6}(1988-92)$ & $\cdots$ & $\begin{array}{c}3.01 \\
(3.86)\end{array}$ & $\begin{array}{l}3.15 \\
(4.11)\end{array}$ & . . & $\begin{array}{c}2.95 \\
(3.54)\end{array}$ \\
\hline \multicolumn{6}{|l|}{ Summary Statistic } \\
\hline $\begin{array}{l}\overline{\mathbf{R}}^{2} \\
\text { SER }\end{array}$ & $\begin{array}{l}0.77 \\
1.72\end{array}$ & 0.83 & $\begin{array}{l}0.83 \\
150\end{array}$ & $\begin{array}{l}0.81 \\
1.51\end{array}$ & $\begin{array}{l}0.83 \\
1.54\end{array}$ \\
\hline SSR & 422 & 309 & 311 & 141 & 164 \\
\hline \multicolumn{6}{|l|}{$\begin{array}{l}\text { Addendum } \\
\text { All } \gamma \text { constrained to be }\end{array}$} \\
\hline $\begin{array}{l}\text { equal } \\
y \text { coefficient }\end{array}$ & $\cdots$ & $\begin{array}{l}2.57 \\
(6.98)\end{array}$ & $\begin{array}{l}2.68 \\
(7.55)\end{array}$ & $\begin{array}{c}2.54 \\
(5.18)\end{array}$ & $\begin{array}{r}2.89 \\
(5.25)\end{array}$ \\
\hline SER & $\ldots$ & 1.49 & 1.48 & 1.49 & 1.52 \\
\hline
\end{tabular}

Source: Author's regressions using data described in table 1.

a. The regressions estimate variations of equation 1 in the text: $\left(\Delta h-\Delta h^{*}\right)_{t}=\mu+\sum_{i=k}^{L} \alpha_{i}\left(\Delta h-\Delta h^{*}\right)_{t-i}+$ $\sum_{j=m}^{N} \beta_{j}\left(\Delta q-\Delta q^{*}\right)_{t-j}+\phi\left[(q-h)-\left(q^{*}-h^{*}\right)\right]_{t-1}+\sum_{k=1}^{6} \gamma_{k} D_{k}+\epsilon_{t}$. The dependent variable is the change in the $\log$ of hours relative to trend. The numbers in parentheses are $t$-statistics. 
sion coefficients on the six separate episodes are of roughly the same size, I reran the equations to constrain the six separate $\gamma_{i}$ coefficients to be the same and determined that they are not significantly different from one another. ${ }^{37}$ The constrained value of $\gamma$ is about 2.7 , as shown in the bottom section of table 5, implying cumulative overhiring of 2.7 percent during the EOE period, followed by a subsequent correction of 2.7 percent.

The last two regressions show that the coefficients for the two subperiods are very close to those for the entire 1954-92 period. A Chow test fails to reject the hypothesis of structural stability; the F test $(8,131)$ is 0.49 , compared to the 5 percent critical value of 2.01 . Finally, the sums of the $\alpha$ and $\beta$ coefficients imply that the elasticity of hours deviations to output deviations is $\beta /(1-\alpha)=0.72$, and hence the response of ALP to output deviations from trend has an elasticity of 0.28 . A dynamic simulation of the estimated equation indicates that initially hours adjust by less than this response, and that four quarters are required for the response of hours deviations to output deviations to arrive at the value of 0.72 .

\section{Summarizing the Specification: The Four Frequencies of Productivity}

The specification of hours adjustment in equation 1 implies that there are four different time frequencies relevant for productivity analysis. At the highest frequency, the deviation from trend of labor input adjusts with a lag distribution spreading over four calendar quarters to deviations from trend of output, and as a result, productivity movements lead those in output by a few months. This high-frequency movement occurs with the same lead-lag pattern whether the business cycle lasts two years or ten. The second frequency is cyclical and reflects the fact that hours respond to a sustained movement of output away from trend with an elasticity below unity, about 0.72 . Thus ALP responds to a sustained movement of output away from trend with an elasticity of about 0.28 . The third frequency is also cyclical. This is the end-of-expansion effect: the slump in productivity that appears to occur repeatedly between the peak of the growth cycle and the peak of the NBER cycle. Finally, the fourth frequency is the trend itself that emerges when the parameters

37. The $F(5,139)$ ratio for the difference in fit between the equations in the third column of table 5, using six different EOE coefficients and a single EOE coefficient, is 0.24 , as compared to the 5 percent critical value of 2.27 . 
Table 6. Estimated Equations for Change in Manufacturing Hours Relative to Trend, 1954:4-1992:4

\begin{tabular}{|c|c|c|c|c|c|}
\hline Independent variable & $\begin{array}{l}1954: 4- \\
1992: 4\end{array}$ & $\begin{array}{c}1954: 4- \\
1992: 4\end{array}$ & $\begin{array}{l}1954: 4- \\
1992: 4\end{array}$ & $\begin{array}{l}1954: 4- \\
1972: 4\end{array}$ & $\begin{array}{l}1973: 1- \\
1992: 4\end{array}$ \\
\hline Constant & $\begin{array}{c}0.38 \\
(1.63)\end{array}$ & $\begin{array}{c}0.20 \\
(0.86)\end{array}$ & $\cdots$ & $\cdots$ & $\cdots$ \\
\hline $\begin{array}{l}\text { Lagged dependent } \\
\qquad\left(\Delta h-\Delta h^{*}\right)\end{array}$ & $\begin{array}{c}0.37 \\
(3.77)\end{array}$ & $\begin{array}{c}0.12 \\
(1.14)\end{array}$ & $\begin{array}{c}0.09 \\
(0.85)\end{array}$ & $\begin{array}{c}0.03 \\
(0.22)\end{array}$ & $\begin{array}{c}0.05 \\
(0.59)\end{array}$ \\
\hline $\begin{array}{l}\text { Output deviation } \\
\qquad\left(\Delta q-\Delta q^{*}\right)\end{array}$ & $\begin{array}{c}0.48 \\
(5.47)\end{array}$ & $\begin{array}{c}0.62 \\
(6.84)\end{array}$ & $\begin{array}{c}0.66 \\
(7.89)\end{array}$ & $\begin{array}{c}0.74 \\
(5.87)\end{array}$ & $\begin{array}{c}0.66 \\
(5.77)\end{array}$ \\
\hline Error-correction term & $\begin{array}{c}0.20 \\
(2.39)\end{array}$ & $\begin{array}{c}0.10 \\
(1.33)\end{array}$ & $\ldots$ & $\ldots$ & $\ldots$ \\
\hline \multicolumn{6}{|l|}{$\begin{array}{l}\text { End-of-expansion } \\
\text { dummies }\end{array}$} \\
\hline$\gamma_{1}(1955-58)$ & $\ldots$ & $\begin{array}{c}1.98 \\
(1.98)\end{array}$ & $\begin{array}{l}2.11 \\
(2.12)\end{array}$ & $\begin{array}{l}2.00 \\
(2.01)\end{array}$ & $\cdots$ \\
\hline$\gamma_{2}(1959-62)$ & $\cdots$ & $\begin{array}{l}1.35 \\
(1.22)\end{array}$ & $\begin{array}{c}1.44 \\
(1.30)\end{array}$ & $\begin{array}{c}1.13 \\
(1.05)\end{array}$ & $\cdots$ \\
\hline$\gamma_{3}(1968-71)$ & $\ldots$ & $\begin{array}{c}2.70 \\
(2.60)\end{array}$ & $\begin{array}{l}2.79 \\
(2.70)\end{array}$ & $\begin{array}{c}2.71 \\
(2.64)\end{array}$ & $\cdots$ \\
\hline$\gamma_{4}(1973-76)$ & $\ldots$ & $\begin{array}{c}2.45 \\
(2.21)\end{array}$ & $\begin{array}{l}2.60 \\
(2.36)\end{array}$ & $\ldots$ & $\begin{array}{c}3.33 \\
(2.72)\end{array}$ \\
\hline$\gamma_{5}(1978-82)$ & $\ldots$ & $\begin{array}{c}3.74 \\
(3.13)\end{array}$ & $\begin{array}{c}4.24 \\
(3.72)\end{array}$ & $\cdots$ & $\begin{array}{c}4.46 \\
(3.65)\end{array}$ \\
\hline$\gamma_{6}(1988-92)$ & $\cdots$ & $\begin{array}{l}1.35 \\
(1.22)\end{array}$ & $\begin{array}{c}1.50 \\
(1.36)\end{array}$ & $\ldots$ & $\begin{array}{c}1.82 \\
(1.60)\end{array}$ \\
\hline \multicolumn{6}{|l|}{ Summary Statistic } \\
\hline$\overline{\mathrm{R}}^{2}$ & 0.86 & 0.88 & 0.88 & 0.89 & 0.87 \\
\hline SER & 2.40 & 2.29 & 2.28 & 2.16 & 2.31 \\
\hline SSR & 824 & 716 & 725 & 290 & 368 \\
\hline \multicolumn{6}{|l|}{ Addendum } \\
\hline $\begin{array}{l}\text { equal } \\
\gamma \text { coefficient }\end{array}$ & $\cdots$ & $\begin{array}{c}2.16 \\
(4.18)\end{array}$ & $\begin{array}{c}2.37 \\
(4.72)\end{array}$ & $\begin{array}{c}1.96 \\
(3.00)\end{array}$ & $\begin{array}{c}3.10 \\
(3.94)\end{array}$ \\
\hline SER & $\ldots$ & 2.27 & 2.28 & 2.15 & 2.32 \\
\hline
\end{tabular}

Source and notes: See table 5.

governing the other three frequencies are identified; the loglinear trendsthrough-benchmarks technique allows the trend to vary from one business cycle to the next.

\section{Estimation: The Two Subsectors}

Tables 6 and 7 display estimated parameters in the same format as table 5 for the manufacturing and NFNM sectors. As would be expected, 
Table 7. Estimated Equations for Change in Nonfarm Nonmanufacturing Business Hours Relative to Trend, 1954:4-1992:4

\begin{tabular}{|c|c|c|c|c|c|}
\hline Independent variable & $\begin{array}{l}1954: 4- \\
1992: 4\end{array}$ & $\begin{array}{l}1954: 4- \\
1992: 4\end{array}$ & $\begin{array}{l}1954: 4- \\
1992: 4\end{array}$ & $\begin{array}{l}1954: 4- \\
1972: 4\end{array}$ & $\begin{array}{l}1973: 1- \\
1992: 4\end{array}$ \\
\hline Constant & $\begin{array}{c}0.23 \\
(1.27)\end{array}$ & $\begin{array}{l}0.13 \\
(0.75)\end{array}$ & $\cdots$ & $\cdots$ & $\cdots$ \\
\hline $\begin{array}{l}\text { Lagged dependent } \\
\quad\left(\Delta h-\Delta h^{*}\right)\end{array}$ & $\begin{array}{c}0.08 \\
(0.70)\end{array}$ & $\begin{array}{l}-0.36 \\
(-2.51)\end{array}$ & $\begin{array}{l}-0.40 \\
(-2.86)\end{array}$ & $\begin{array}{l}-0.60 \\
(-2.60)\end{array}$ & $\begin{array}{l}-0.30 \\
(-1.66)\end{array}$ \\
\hline $\begin{array}{l}\text { Output deviation } \\
\qquad\left(\Delta q-\Delta q^{*}\right)\end{array}$ & $\begin{array}{c}0.59 \\
(5.68)\end{array}$ & $\begin{array}{c}0.71 \\
(6.98)\end{array}$ & $\begin{array}{c}0.77 \\
(8.49)\end{array}$ & $\begin{array}{c}0.65 \\
(3.99)\end{array}$ & $\begin{array}{c}0.81 \\
(7.10)\end{array}$ \\
\hline Error-correction term & $\begin{array}{c}0.27 \\
(2.67)\end{array}$ & $\begin{array}{c}0.15 \\
(1.51)\end{array}$ & $\ldots$ & $\ldots$ & $\ldots$ \\
\hline \multicolumn{6}{|l|}{$\begin{array}{l}\text { End-of-expansion } \\
\text { dummies }\end{array}$} \\
\hline$\gamma_{1}(1955-58)$ & $\ldots$ & $\begin{array}{l}1.98 \\
(2.37)\end{array}$ & $\begin{array}{l}2.06 \\
(2.46)\end{array}$ & $\begin{array}{l}2.86 \\
(2.84)\end{array}$ & $\cdots$ \\
\hline$\gamma_{2}(1959-62)$ & $\cdots$ & $\begin{array}{l}2.19 \\
(2.37)\end{array}$ & $\begin{array}{l}2.21 \\
(2.39)\end{array}$ & $\begin{array}{l}2.52 \\
(2.50)\end{array}$ & $\ldots$ \\
\hline$\gamma_{3}(1968-71)$ & $\cdots$ & $\begin{array}{l}2.13 \\
(2.46)\end{array}$ & $\begin{array}{l}2.37 \\
(2.79)\end{array}$ & $\begin{array}{l}2.72 \\
(2.91)\end{array}$ & $\cdots$ \\
\hline$\gamma_{4}(1973-76)$ & $\cdots$ & $\begin{array}{l}2.75 \\
(2.96)\end{array}$ & $\begin{array}{l}2.97 \\
(3.24)\end{array}$ & $\ldots$ & $\begin{array}{l}2.65 \\
(2.82)\end{array}$ \\
\hline$\gamma_{5}(1978-82)$ & $\cdots$ & $\begin{array}{l}2.05 \\
(2.13)\end{array}$ & $\begin{array}{l}2.28 \\
(2.39)\end{array}$ & $\ldots$ & $\begin{array}{c}1.86 \\
(1.92)\end{array}$ \\
\hline$\gamma_{6}(1988-92)$ & $\cdots$ & $\begin{array}{c}3.79 \\
(3.69)\end{array}$ & $\begin{array}{l}4.03 \\
(3.96)\end{array}$ & $\ldots$ & $\begin{array}{c}3.56 \\
(3.36)\end{array}$ \\
\hline \multicolumn{6}{|l|}{ Summary Statistic } \\
\hline SER & 2.03 & 1.89 & $\begin{array}{l}0.89 \\
1.89\end{array}$ & $\begin{array}{l}0.40 \\
1.98\end{array}$ & 1.84 \\
\hline SSR & 592 & 490 & 498 & 242 & 234 \\
\hline \multicolumn{6}{|l|}{ Addendum } \\
\hline $\begin{array}{c}\text { equal } \\
\gamma \text { coefficient }\end{array}$ & $\cdots$ & $\begin{array}{c}2.34 \\
(5.09)\end{array}$ & $\begin{array}{c}2.52 \\
(5.60)\end{array}$ & $\begin{array}{c}2.69 \\
(4.20)\end{array}$ & $\begin{array}{c}2.60 \\
(3.85)\end{array}$ \\
\hline SER & $\ldots$ & 1.88 & 1.88 & 1.95 & 1.84 \\
\hline
\end{tabular}

Source and notes: See table 5 .

because NFNM makes up three-quarters of the nonfarm business aggregate, the results in table 7 are quite similar to those in table 5 . The elasticity of hours to output, $\beta$, is lower, possibly reflecting measurement error, the goodness of fit is worse, and the end-of-expansion dummies tend to have lower $t$-ratios than in table $5 .^{38}$

38. The EOE dummies are identical in the two subsectors as in the aggregate; no searching was done to locate the best-fitting timing of the correction period. 
Table 6 reflects the higher volatility of manufacturing hours and output; both the $\overline{\mathrm{R}}^{2}$ and the standard error of estimate are higher than in table 5 . In all columns of table 6 , the response of hours deviations to output deviations is smaller over the first four quarters than for the nonfarm business sector in table 5; this implies that, on average, productivity displays a larger response to cyclical output deviations in the manufacturing sector than in the total economy.

An interesting result is that in the 1988-92 cycle, the end-of-expansion effect in manufacturing is unusually low and in NFNM is unusually high. In contrast, the end-of-expansion effect in manufacturing was unusually high for 1978-82, the "Rust Belt" episode. These estimated coefficients support the thrust of popular commentary. The early 1980s witnessed an unusually savage downsizing of manufacturing employment, whereas the early 1990s have witnessed a corporate downsizing movement in the NFNM sector. The difference between the journalistic version of these episodes and my econometric version, however, is that in each case there was end-of-expansion overhiring that preceded the downsizing. Journalists, by contrast, focus on the firings and layoffs, while omitting mention of the overhiring that came earlier.

\section{The Underlying Trend in Labor's Average Product, 1987-92}

The specification of the econometric equation estimated in the previous section requires that the first difference of hours and of output be expressed as deviations from trend. For the period through 1987, loglinear trends are extended between the benchmark quarters listed in table 3. However, there is no benchmark quarter after 1987, because at the end of the sample period in late 1992, the unemployment rate remained well above its natural rate of about 6 percent. ${ }^{39}$ All the estimates discussed in the previous section assume arbitrarily that the productivity trend recorded in 1972-87 continues during $1987-92 .{ }^{40}$ In this section, I

39. Recall that the criteria for a benchmark quarter are that the unemployment rate is close to the natural rate, currently about 6 percent; that the unemployment rate is falling (thus ruling out the period in late 1990 when the unemployment rate was 6 percent but unemployment was rising); and that the end-of-expansion effect is nonoperative.

40. More precisely, a trend for hours is established for each of the three sectors, and then the output trend is equal to the hours trend plus the assumed productivity trend. To fix the hours trend in all the regressions estimated in tables 4-7, I assumed that a 6 percent 
search for the optimal 1987-92 productivity trend that yields the bestfitting equations estimated for the period 1973-92.

\section{Cumulative 1987-92 Errors in Alternative Equations}

To illustrate the sensitivity of the results to the form of the specification, figure 5 displays cumulative forecasting errors over the 1987:41992:4 period for the nonfarm business sector. There are three frames in the diagram, corresponding to three different versions of the equation, each estimated over the 1973-92 interval. In each frame, cumulative errors are shown for three different assumptions about the 1987-92 productivity trend.

The top frame uses the version of the equation that excludes the endof-expansion terms but includes the error-correction term. (This version corresponds to the first regression of table 5, reestimated for the shorter 1973-92 period.) No matter whether the assumed 1987-92 productivity trend is $0.75,1.00$, or 1.25 percent per year, this version of the equation makes large positive forecasting errors, implying that the growth of actual labor input during 1987-91 is substantially larger than the equation predicts. Furthermore, the cumulative error is eliminated by slow hours growth of 1992 only when the 1987-92 productivity trend is set at a relatively low 0.75 percent per year.

The middle frame uses the version of the equation that excludes the error-correction term and includes the end-of-expansion dummy variables. (This frame corresponds to the last regression estimated in table 5.) The cumulative errors plotted in the middle frame are much smaller than those in the top frame because much of the excess growth of hours in the 1989-90 period is explained by the end-of-expansion dummy (which has its "on" phase during 1989:1-1990:3). The cumulative error at the end of the period in 1992:4 is closest to zero with a relatively slow assumed productivity trend of 1.00 percent per year.

unemployment rate (in contrast to the 7.3 percent unemployment rate recorded in 1992:4) would require a level of hours 1.6 percent higher than actually occurred in 1992:4. Of this 1.6 percent difference, 1.2 percent is required to reduce the unemployment rate to 6 percent, and the remaining 0.4 percent is assumed to be reflected in some combination of higher hours per employee and a higher labor force participation rate. The implied annual trend growth rate of hours during 1987:3-1992:4 is 0.87 percent for nonfarm business, -0.56 for manufacturing, and 1.32 percent for NFNM. 
Figure 5. Cumulative Forecasting Errors for Nonfarm Business Hours, 1987:4-1992:4 a

Percent
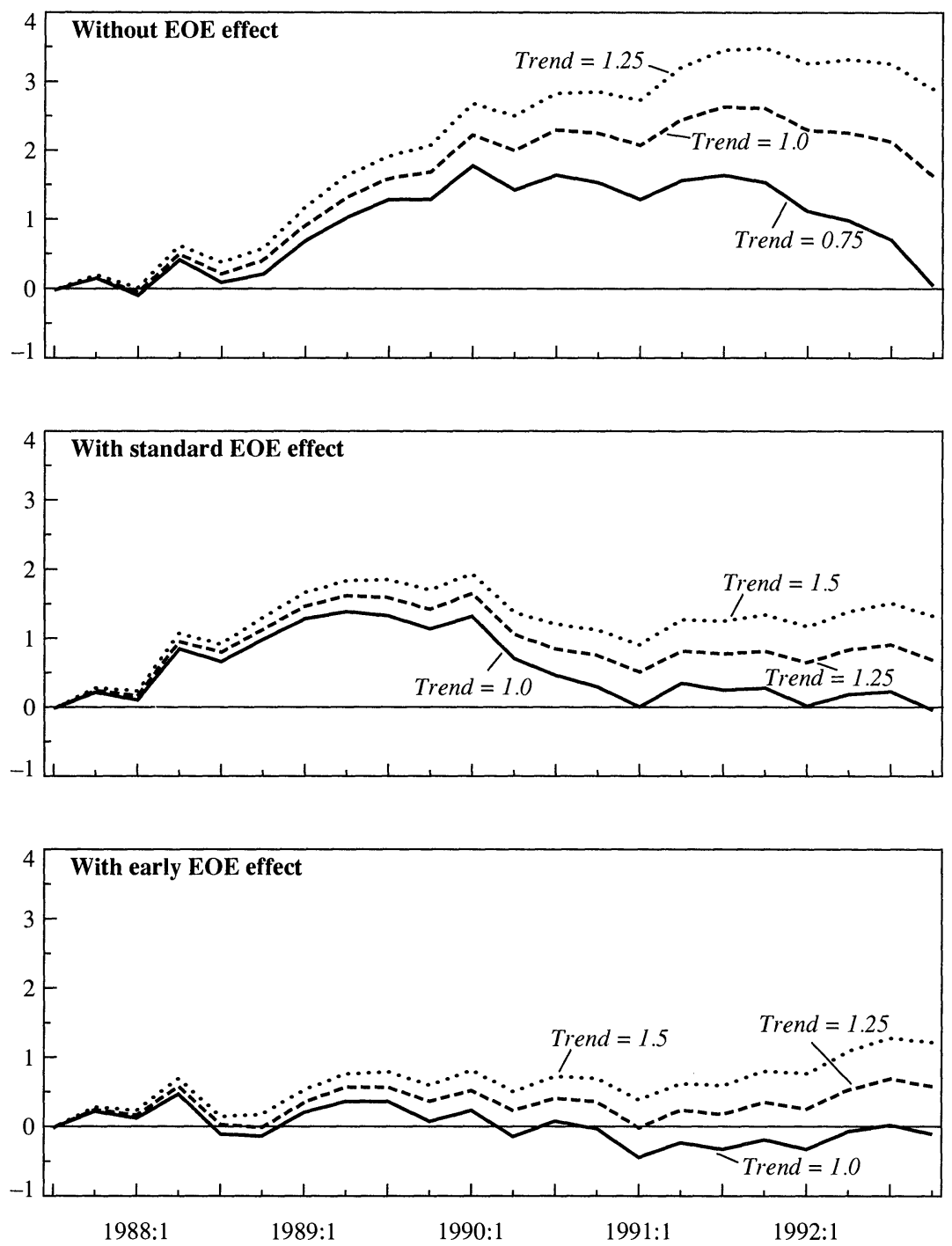

Source: Author's calculations.

a. Each panel depicts the forecasting errors using three different assumptions about the 1987-92 productivity trend. The panels differ in terms of equation specification as follows. The first panel uses the specification of the first regression estimated in table 5 with an error-correction term and no EOE dummies, but estimates it for the shorter period of 1973:1-1992:4. The second panel uses the specification of the last regression estimated in table 5, which includes EOE dummies but excludes an error-correction term. The third panel's specification is similar to second panel's, except that the EOE term has its "on" phase one year earlier, from 1988:1-1989:3. 
However, in the middle frame the cumulative errors display a consistent hump-shaped pattern that is independent of the assumed trend. This occurs because the equation cannot explain why hours growth was so rapid (or productivity growth was so slow) during 1988, before the onset of the EOE interval. To determine how this early initiation of overhiring interacts with the underlying trend, I define an alternative EOE variable which has its "on" phase one year earlier (1988:1-1989:3) than the standard variable, but retains the same definition of the correction ("off") phase. The cumulative errors with this alternative early EOE variable are plotted in the bottom frame of figure 5 and are much closer to zero. There is little impact on the trend; the trend that brings the cumulative error closest to zero in 1992:4 is 1.00 percent per year, just as in the middle frame with the standard EOE definition.

\section{Searching for the Optimal Trend}

Figure 5 displays various assumed trends. The analysis can be extended by conducting a grid search for the best-fitting trend for each sector and for each version of the specification. Table 8 displays the actual 1972-87 growth rates of productivity with and without correction for the base-year data bias, the optimal 1987-92 trends resulting from the grid search, and the residual for each equation during the final four quarters of the sample period ending in 1992:4. A negative residual means that hours growth is overpredicted in 1992: that is, productivity grew faster than the equation can explain.

The first section of the table displays results for the nonfarm business sector-the same sector displayed in figure 5; the results are consistent with that graph. The optimal $1987-92$ trend is only 0.73 percent when the EOE effect is excluded, but a more robust 1.10 percent when the EOE effect is included. The 1992 residual with the EOE effect is only -0.27 percent.

The second and third sections of table 8 display optimal trends for the manufacturing and NFNM sectors. For each sector, the inclusion of the EOE effect raises the optimal 1987-92 trend. The inclusion of the EOE effect reduces the residuals for 1992, making them negative in both sectors. The EOE effect makes little difference to the absolute size of the manufacturing residual for 1992 but substantially reduces the absolute size of the 1992 residual in the NFNM sector. The fourth section of the 
Table 8. Best-Fitting Productivity Growth Trends

Percent per year

\begin{tabular}{|c|c|c|c|c|c|}
\hline \multirow[b]{2}{*}{ Sector } & \multirow[b]{2}{*}{ Equation type } & \multicolumn{2}{|c|}{$\begin{array}{c}\text { Actual Growth Rate } \\
1972: 2-1987: 3\end{array}$} & \multirow{2}{*}{$\begin{array}{l}\text { Optimal } \\
\text { trend, } \\
1987: 3- \\
1992: 4\end{array}$} & \multirow{2}{*}{$\begin{array}{c}\text { Mean } \\
\text { residual, } \\
1992: 1- \\
1992: 4\end{array}$} \\
\hline & & Official & $\begin{array}{l}\text { Benchmark } \\
\text { reweighted }\end{array}$ & & \\
\hline \multirow{2}{*}{$\begin{array}{l}\text { Nonfarm } \\
\text { business }\end{array}$} & No EOE effect & 0.98 & 1.28 & 0.73 & -1.16 \\
\hline & With EOE effect & 0.98 & 1.28 & 1.10 & -0.27 \\
\hline \multirow[t]{2}{*}{ Manufacturing } & No EOE effect & 2.13 & 3.13 & 2.51 & 0.46 \\
\hline & With EOE effect & 2.13 & 3.13 & 2.65 & -0.45 \\
\hline \multirow{2}{*}{$\begin{array}{l}\text { Nonfarm } \\
\text { nonmanufacturing } \\
\text { business }\end{array}$} & No EOE effect & 0.48 & 0.46 & 0.03 & 1.04 \\
\hline & With EOE effect & 0.48 & 0.46 & 0.66 & -0.32 \\
\hline \multirow{2}{*}{$\begin{array}{l}\text { Nonfarm } \\
\text { business aggre- } \\
\text { gated from sub- } \\
\text { sectors }\end{array}$} & No EOE effect & 0.98 & 1.28 & 0.78 & 0.86 \\
\hline & With EOE effect & 0.98 & 1.28 & 1.26 & -0.36 \\
\hline
\end{tabular}

Source: Author's calculations based on Bureau of Labor Statistics, Productivity and Costs.

a. All equations are estimated from 1973:1-1992:4. The best-fitting trends are those that minimize the root squared error of the particular equation over 1987:4-1992:4.

table displays the weighted average of the two subsectors; the implied optimal productivity trend for the nonfarm business sector is 1.26 percent per year, more rapid than the direct estimate of 1.10 percent in the first section. In view of the numerous sources of measurement error in the subsector data, the direct estimates in the first section are probably more reliable than the estimates in the fourth section based on subsector data.

\section{Interpreting Cyclical Fluctuations in Productivity}

The distinguishing feature of productivity change in the aggregate economy over the past five years is a long period of zero growth during 1987-91, followed by a sharp upsurge in 1992. Can this record be interpreted as normal cyclical behavior? The performance of the basic equation (with the standard EOE effect and optimal 1987-92 trend of 1.10 percent) is plotted in figure 6. The actual and predicted values of labor productivity and the deviation of productivity from its assumed trend are displayed.

The equation does an acceptable job of tracking cyclical fluctuations in productivity, and in fact performs better in 1987-92 than in previous 
Figure 6. Actual and Predicted Productivity for Nonfarm Business, 1973-92 a

Index, $1972: 2=100$

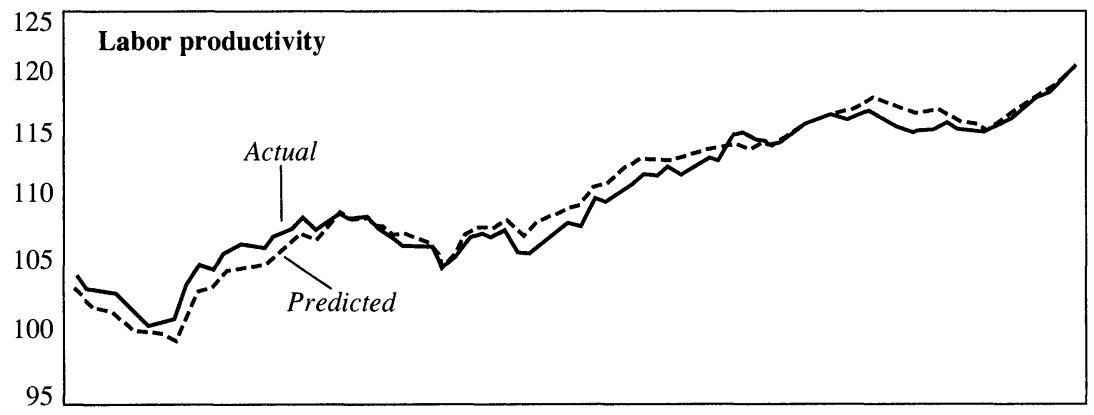

Percent

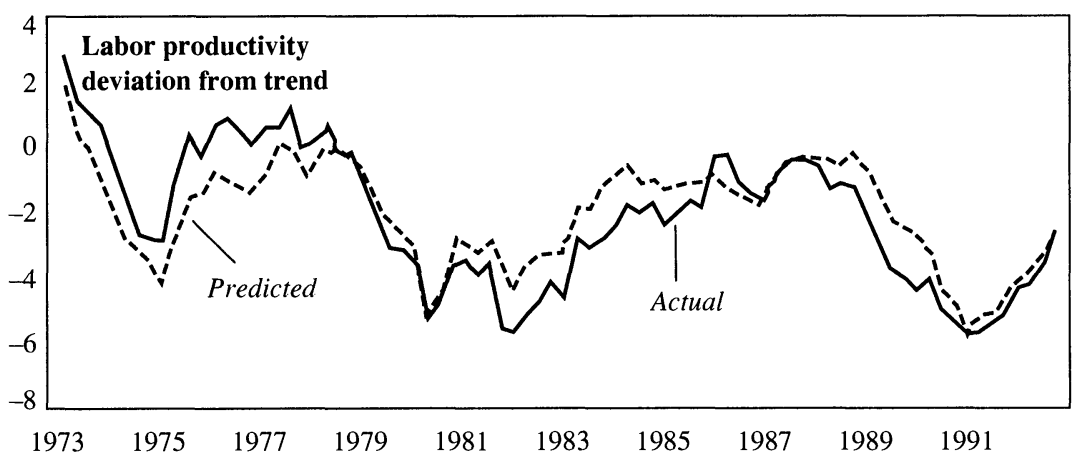

Source: Author's calculations.

a. The 1987-92 assumed productivity trend is 1.1 , and the equation estimated includes standard-timing EOE effects.

cyclical episodes. The appearance of serial correlation in the plot reflects the fact that the equation is estimated in first differences (where no serial correlation exists), but plotted in levels. The errors in figure 6the actual values minus the predicted values-are computed by cumulating the first-difference equation residuals beginning in the first quarter of the sample period (1973:1). These errors are thus equivalent to the cumulative errors plotted in figure 5. The equations tend to predict too large a decline in productivity and subsequent recovery in the 1973-77 period and too small a decline in productivity in the 1982 recession. As noted above, the equation with the standard timing of the 1989-90 EOE 
Table 9. Alternative Growth Rate Forecasts for Nonfarm Business, Four Quarters Ending 1993:4 and 1994:4 ${ }^{a}$

Percent per year

\begin{tabular}{cccccc}
\hline & \multicolumn{2}{c}{ Hours } & & \multicolumn{2}{c}{ Output per hour } \\
\cline { 2 - 3 } \cline { 5 - 6 } Forecast specification & $1993: 4$ & $1994: 4$ & & $1993: 4$ & $1994: 4$ \\
\hline $\begin{array}{c}\text { No EOE effect and pro- } \\
\text { ductivity trend of } 0.73\end{array}$ & 2.48 & 2.53 & 0.72 & 0.67 \\
$\begin{array}{c}\text { Standard EOE effect and } \\
\text { productivity trend of } \\
\quad\end{array}$ & 1.68 & 1.89 & 1.52 & 1.32 \\
$\begin{array}{c}\text { Early EOE effect and pro- } \\
\text { ductivity trend of } 1.10\end{array}$ & 1.53 & 1.84 & & 1.67 & 1.36 \\
\hline
\end{tabular}

Source: Authors calculations.

a. The assumed output growth rate is 3.2 percent per year.

effect also misses the overhiring that occurred in 1988, and hence its prediction of the late 1980s decline in productivity occurs about a year too late. However, the prediction of the 1991-92 recovery of productivity is right on track. The predicted deviation of productivity from trend in $1992: 4$ is -2.5 percent, implying that there is substantial room for productivity growth to proceed at a rate above the assumed 1.1 percent trend during 1993-95 without implying a need to reassess the trend. ${ }^{41}$

\section{Forecasts for 1993-94}

For any assumed growth rate of output in 1993-94, each of the equations can be used to divide output between a predicted path of hours growth and a residual path of productivity growth. For output growth, I assume a steady annual growth rate during the eight quarters of 1993-94 of 3.2 percent per year, the current consensus of the blue chip group of economic forecasters. The productivity trend is the optimal rate listed in the first section of table 8 .

As shown in table 9, all equations forecast substantial growth in hours, in contrast to the zero growth that characterized 1992. The two alternative equations-based on standard and early EOE effects-predict productivity growth in the range of 1.5-1.7 percent for 1993 and 1.31.4 percent for 1994 . These relatively slow rates of productivity growth

41. Productivity growth during the three years $1993-95$ at a rate of 1.93 percent per year would bring the deviation from trend back to zero in 1995:4. 
would leave the deviation from trend (as plotted in the bottom of figure 6) still from -1.7 to -1.9 percent in 1994:4. The failure of productivity to recover to its trend is the counterpart of the assumed 3.2 percent growth rate of output, a much slower rate than at the same stage of previous business-cycle expansions.

\section{Conclusion}

The performance of average labor productivity and multifactor productivity in the U. S. economy was dismal from 1972 to 1991 . Does the relatively rapid growth in ALP and MFP experienced in 1991-92 warrant optimism that relief has arrived from the two-decade-long productivity growth slowdown? The answer depends on whether the recent experience represents an acceleration in the underlying long-term trend or just a normal cyclical upturn that is similar to behavior in previous business cycles. To provide the answer, this paper proposes a method for separating trend from cycle.

I show that cyclical productivity does not simply parallel the cycle in output that determines the dates of NBER peaks and troughs. Instead, productivity displays complex cyclical behavior that can be decomposed into three different time frequencies. First is the high-frequency movement caused by the relatively short lag of hours behind output; this adjustment in hours is completed within four quarters after a change in output relative to trend. Second, the adjustment of hours within the first four quarters has a cumulative elasticity to output of 0.72 , leaving a positive elasticity of ALP to deviations in output from trend that lasts until these deviations disappear-that is, for the duration of the business cycle. Third, productivity systematically displays an end-of-expansion slump between the peak in the growth cycle (the peak for detrended output) and the NBER peak (defined for the absolute level of output); a correction in the two years or so after the NBER peak follows; during this correction period, productivity growth is more rapid than would be predicted on the basis of output growth alone. I interpret this phenomenon as the result of overoptimism by business firms that is subsequently corrected.

This paper provides strong support for the end-of-expansion effect. This phenomenon, originally proposed in 1979 and based largely on cy- 
clical behavior through the mid-1970s, has now recurred in two more cyclical episodes, 1978-82 and 1989-93. Equations that include the end-ofexpansion effect provide a much improved fit of the data and are quite robust, passing a test for structural stability over the full 1954-92 period. The 1988-91 decline in productivity relative to trend and the subsequent 1991-92 recovery are tracked quite accurately. As a byproduct, inclusion of the end-of-expansion effect provides a more optimistic interpretation of the trend in productivity growth over the past five years than an equation that omits this effect.

For two alternative definitions of the end-of-expansion effect, the best-fitting 1987-92 productivity trend for the private nonfarm economy is 1.1 percent per year. When the best-fitting trends are determined separately for the manufacturing and nonfarm nonmanufacturing sectors and then aggregated, the result is 1.26 percent per year. Both of these rates are below the actual $1972-87$ growth rate of 1.28 percent per year obtained by correcting the bias in the official data that arises from its fixed 1987 weighting scheme. The best-fitting 1987-92 trends at the sectoral level imply that there has been a substantial 0.5 percent per year deceleration in the growth rate of manufacturing productivity as compared to the 1972-87 growth rate corrected for the base-year data bias, offset by a modest 0.2 percent acceleration for the nonfarm nonmanufacturing sector.

How does the econometric investigation assess the widespread journalistic view that a new era of productivity-led growth is at hand? The only way to emerge with an optimistic conclusion is to focus entirely on 1991-92 and ignore the productivity stagnation of 1987-91. Those who would argue that there was a one-shot jump of productivity in 1992, as opposed to a normal cyclical correction of the type that has occurred repeatedly in past cycles, are forced to conclude that the trend from 1972 to 1991 is even more dismal than previously believed.

However, the detailed analysis does provide a few glimmers of support for some aspects of the popular view. First, the end-of-expansion effect estimated for the 1989-92 episode is among the largest on record, with an estimate of 3.2 percent cumulative overhiring (followed by a cumulative 3.2 percent decline during 1991-93 in labor input relative to the level implied by output growth). Second, the end-of-expansion effect in the recent episode has been much smaller than usual in manufacturing and much larger than usual in NFNM. Both these conclusions support 
the journalistic view that the current wave of corporate downsizing and restructuring is unusual, both in its size and in its concentration in the service sector and in white-collar occupations.

What the popular view misses quite consistently, however, is that the wave of downsizing does not emerge out of thin air but is the direct result of extensive overhiring in the NFNM sector during the late 1980s. If the economic difficulties of the early 1990s come to be labeled generally as an economic hangover, then the jobless recovery of 1991-92 can be viewed as a hangover reaction to a binge of overhiring in the late 1980sjust as sluggish spending by consumers and business firms has come to be viewed widely as a hangover reaction to excess indebtedness incurred in the mid- to late 1980s. Perhaps the business press could be urged to replace the common expression "corporate restructuring" with the more appropriate phrase, "correcting our past mistakes." 


\section{Comments and Discussion}

Martin Neil Baily: I will comment first on the specific empirical results given in this paper, and then will talk more generally about the productivity trend and the nature of the short-term cyclical productivity puzzle. Based on his earlier work, Robert Gordon argues that a surge in productivity is a normal cyclical pattern, the counterpart to a period of very weak productivity growth or of productivity decline that precedes recessions. He has identified this pattern and labeled it an end-of-expansion effect and a subsequent bounceback.

I have found this story to be a pretty good one. Both George Perry and Charlie Schultze have told me that they burned their fingers back in the 1970s arguing that the very rapid productivity growth that accompanied the recovery from the 1974-75 recession was a sign that no longterm decline in the productivity growth trend had occurred, when in fact the improvement turned out to be ephemeral. In Charlie Schultze's case, this contributed to an overestimate of the amount of slack in the economy and an underestimate of the dangers of inflation in the late 1970s. I burned my own fingers in 1984 arguing the same thing; once again, the productivity trend, at least for the business sector as a whole, showed little improvement. The growth of productivity in recoveries makes it easy to believe mistakenly that the growth trend has improved. As Yogi Berra put it, the current wave of productivity optimism may be déjà $v u$ all over again.

In this paper, Gordon starts by running the smoothing package of Robert Hodrick and Edward Prescott. The results from this analysis support the view that no significant change in the trend has occurred. No 
value of the smoothing parameter gives a predicted trend in the past few years that is significantly higher than the trend from 1972 to 1987.

Second, Gordon uses his preferred estimation technique of fitting piecewise linear trends to "break points," defined as quarters with roughly similar unemployment rates and during which unemployment is falling. He adds his dummy variables for the end-of-expansion collapse and the subsequent bounceback. His basic results indicate that the bounceback variable easily accounts for the recent growth spurt. Gordon finds that there has been a 12 to 28 basis point improvement in the trend since 1987. But as he points out, this much of an improvement is not an indication of a real increase in the pace of productivity growth, because the use of base-year prices biases growth up in years after the base year, and down in years prior to the base year. The bias is about 30 basis points prior to 1987 .

What might be wrong with Gordon's approach? He made judgment calls that could have been made in other ways with different results. First, Gordon chooses his break points in a way that may help his result along. They occur well before the economy has reached a peak and do not always precede the peak by the same period. For example, very rapid productivity growth occurred in 1972 and 1973; many other economists have placed this event in the pre-slowdown period. This makes the slowdown look worse and the chances of recovery look better. Gordon's break point, in contrast, occurs in early 1972; this puts the 197273 growth into the post-slowdown period and makes it harder to find a recovery.

Second, in his previous work of this kind and in an earlier version of this paper, Gordon chose the timing of the end-of-expansion dummies after peeking at the data. This procedure carries the danger that the timing was chosen to get rid of some pesky residuals, leading to an upward bias in the estimated size of the effects he is capturing. In this version of his paper, he has adopted a suggestion by James Tobin and dated the dummies by the onset of the "growth recessions" that occur prior to the full-fledged NBER recessions. This is a much better procedure and I applaud Gordon for adopting it, but it does not eliminate the problem completely. The fact that Gordon ends up with lower coefficients and $t$-statistics after making the change in specification reinforces the concern about adding a series of dummies, rather than linking these movements in productivity to other observable economic data. 
Third, the specification assumes that the end-of-expansion collapse is worked off in the recovery, regardless of the strength of that recovery. In his basic specification, the end-of-expansion decline in productivity is reversed, even though employment has not recovered overall.

This last point gets me to a key issue, which is also mentioned in the Perry-Schultze paper in this volume. Relative to prior recoveries, productivity growth in this recovery is not that unusual-consistent with there being no change in the productivity trend. On the other hand, relative to past recoveries, the growth of both output and employment in this recovery is very weak and hence very atypical. So achieving strong productivity growth despite very slow output growth could indicate an improvement in the trend of productivity. The reason Gordon reaches his conclusion is that his basic specification is based implicitly on the first interpretation of the historical data. Gordon's timing of the EOE effect (by delaying the rebound period to 1991:4-1993:3) essentially recognizes that perhaps the bounceback in this recovery may not be the same as in prior recoveries because it is so weak. But in the end, he is reinforcing the sense of the arbitrariness of the exact specification and how sensitive the results are to small changes.

I do not believe that the issues can be decided based upon the data that have been put on the table. It is very early in the recovery; we simply do not have enough experience with slow recoveries to be able to tell whether strong productivity growth will continue as the recovery continues or whether output and employment will rise much more closely in step, and hence indicate continued long-term weakness in productivity.

I turn now to a broader perspective. Many of us have been studying the productivity trend for a number of years. Surely we should be able to say what has caused the slowdown and hence whether the reasons for weak growth have been overcome. Unfortunately, there is a lot more uncertainty about the causes of the slowdown than I would like. I wish I had something definitive to offer in this regard, but I do not. Still, I can suggest some helpful measures to examine.

I will list four sources of the slowdown that I would expect to be less of a problem in the 1990s. These provide reasons to expect faster growth in the future. My first source is the idea that slow growth may simply have been a matter of chance. Suppose Robert Solow was right in 1956 and technical change really is exogenous; that is to say, it is not related to anything that we can measure. Solow assumed that total factor pro- 
ductivity grew at a constant rate, but he has made it clear that this was an assumption of modeling convenience. Suppose instead that the productivity trend is a stochastic process. Every few years a productivity trend growth rate is picked, as though one were picking from a set of straws of different lengths. There must be some serial correlation to that stochastic process. This means that because short straws have been picked for twenty years, the expected length of the current straw-that is to say, the expected trend rate of productivity growth over the next five or ten years-is likely to be short, too. On the other hand, some weight surely should be given to the sixty to eighty years prior to 1973 . This was a period of pretty good growth overall. It seems reasonable to expect that growth in the 1990s will be better than it was during the unusually weak years of the 1970s and 1980s. The economy will benefit from regression to the mean.

As a footnote, I realize that this argument could be taken in other directions. If the relevant time horizon is 500 years, not 80 or 100 , then the expected growth rate for the 1990s would be pretty low. Robert Gordon and William Nordhaus have essentially made such an argument, suggesting that the period of rapid innovation and growth in the middle part of the century was anomalous in U.S. economic history. I disagree with this view and prefer to look at the period of industrialization to provide the sample from which parameters are inferred. But that is a matter of taste.

My second source of the slowdown is that the economy experienced some heavy disruptions in the 1970s and 1980s. First, oil prices gyrated, and both ups and downs were costly. Second, entire industries disappeared or were restructured in response to international specialization, changing demand, and deregulation. Third, safety and environmental regulation escalated sharply. Fourth, large demographic changes occurred in the labor market.

Disruptions like these are hard on the economy and make it difficult for managers to concentrate on raising productivity. If further economic disruptions can be avoided, stronger growth can be expected in the 1990s.

My third source of the slowdown is the idea that the electronics revolution soaked up resources that could have been used in other ways and did not provide a growth payoff of its own. Gordon quotes Steve Roach rather disparagingly in his paper. But Roach has been the leading critic 
of overinvestment in computers; he is now arguing that companies are beginning to achieve major gains in productivity because they have learned how to use their information technology effectively. Paul David and other economic historians have reminded us that it takes a long time to absorb a new technology, ${ }^{1}$ so it should come as no surprise that it has taken a while to use computers to raise productivity. Of course, it may be another ten years before the payoff occurs, but Steve Roach now hears a different story from companies, and so do I. This recession has clearly differed from prior recessions in that services have been hit harder than usual, consistent with the idea that restructuring is underway that will raise productivity. One reason to expect faster growth in the 1990s is that the economy can expect to reap the rewards of the heavy investment that has been made in information technology.

My fourth possible source of slow previous growth is that major changes in industrial organization have occurred in the U.S. economy. Deregulation has been substantial, foreign competition has increased, and unions are a much less powerful force in the labor market. These shifts could have hurt productivity in the short run. Deregulation can throw industries into turmoil; the airlines are an obvious example. And unions have been found in some econometric work to be associated with high levels of productivity, so that eliminating unions may have hurt productivity. But competition helps productivity growth, once the adjustment period is over. And nonunion companies seem to achieve higher productivity growth. The increasing competition in the 1970s and 1980s may have served as an investment in growth for the 1990s.

One more source of the productivity slowdown is probably neutral in its impact on future growth. This is measurement error. The quality of measurement in services is weaker than that in manufacturing or other goods production; thus as the locus of employment and innovation shifts toward services, this could lead to an increasing understatement of growth. I consider this factor neutral for the future because I do not know whether the ability of the statistics to capture productivity growth will improve or decline.

What about factors impeding growth? Are there any sources of the 1970s and 1980s slowdown that may continue or even worsen in the 1990s? My first negative is capital. Many people stress that capital in-

1. David (1990). 
vestment is a key element in growth-particularly equipment investment-and that slow capital growth was a source of slow productivity growth. Some of the evidence is a bit iffy, but regardless, the immediate prospects for growth generated by capital investment of all kinds are only fair. The budget deficit can crowd out either domestic investment or net foreign investment. Net foreign investment was crowded out in the 1980s; domestic investment may suffer in the 1990s unless the budget deficit is really controlled.

My second negative is a nonpositive, rather than a true negative. In an earlier discussion of Gordon's paper, I argued that demographic trends were more favorable to growth in the 1990s. But Gordon pointed out that most of this demographic improvement had already taken place by the 1980 s, so demographic trends do not seem to be a promising source of additional growth for the 1990s.

My conclusion from looking at the reasons for the slowdown is that the positives look stronger than the negatives. There are reasonable grounds for hope that growth will be faster in the 1990s. But that is a very subjective choice.

I look now at the nature of the cyclical behavior of productivity. I will distinguish two alternative explanations of it. The first is that labor hoarding occurs. Firms hold excess labor for a while because they think that output will recover. They may do this to preserve firm-specific human capital or to reduce income variance among their workers. An alternative view is that there are increasing returns to scale. For example, a steel mill designed for a certain capacity will run inefficiently with slack capacity. Or an office may be set up with certain tasks allocated to certain people and have only a limited amount of flexibility to let one person cover two jobs, even if both have become effectively part-time jobs.

There is a fine line between these two views. For example, increasing returns may not really be increasing returns if there is enough time to adjust the quasi-fixed factors of production, including the organizational capital involved in allocating tasks. And on the other side, very large amounts of firm-specific human capital (or the availability of alternative tasks, such as training or maintenance, for workers to do) could make labor into a fixed factor over the relevant period of observation. In other words, a model of labor hoarding could be built that was observationally similar to a model of increasing returns. 
Despite this blurring of distinction, labor hoarding is generally short term and temporary and increasing returns are generally longer term. The two approaches imply a timing difference.

The implications of this for the Gordon analysis of trend and cycle are that it affects one's view of the speed or nature of the productivity bounceback. If the cyclical pattern of labor productivity reflects primarily short-term labor hoarding, then the bounceback of productivity in the recovery could be expected to respond to the passage of time. In other words, the basic Gordon specification fits best to a short-term labor hoarding view. If the cyclical pattern of productivity is a reflection of more long-term increasing returns, then the strength of the recovery is crucial. With very slow output and input growth, the economy would not get the productivity effect of restoring efficient full capacity production in industries subject to fundamental increasing returns.

Is there any evidence to choose between these views? There is plenty of anecdotal evidence to support the labor hoarding view; James Medoff reported on a survey a few years back that added to this anecdotal evidence. Of course, increasing returns has been a big player in the recent literature, with support being offered by Robert Hall and others.

The preliminary work that I have done with Eric Bartelsman and John Haltiwanger on plant level data seems to support the increasing returns view. We expected to find that plants that were downsizing employment over a ten-year time horizon would reduce productivity less during recessions. Why hoard labor if you are not going to need it even when the recovery starts? This did not appear to be the case, and so our results did not support the labor hoarding view. Instead, we found the following. Some plants followed a pattern that was consistent with increasing returns over a ten-year time horizon. They experienced either output and input growth and productivity increases or they suffered output and input decline and productivity declines. These plants also experienced large short-term declines in productivity during recession years. In other words, the hypothesis that these plants have increasing returns would help explain not only their ten-year changes, but also their cyclical changes.

I stress that these results are very preliminary and that they only apply to manufacturing. I started out with a prior belief that labor hoarding is important and I have not lost this prior. But for what it is 
worth, these plant-level results are consistent with the view that if a recovery is weak, then a smaller fraction of any observed increase in productivity should be assigned to the cyclical bounceback and a larger fraction to the underlying trend. These results, therefore, make me a little more optimistic about productivity growth over the next few years.

So where do I end up? Gordon is correct that the recent productivity data taken by themselves fail to provide clear evidence of an increase in the productivity trend, or at least evidence of anything more than the pickup that would be expected, given the way output is measured. False optimism has followed the last two recessions, so the cautious policymaker today should not base policy decisions on the assumption that the trend has improved. My advice would be to assume the worst and then wait and see.

Despite this, I remain somewhat optimistic about the future. Nothing in the current data refutes the hypothesis of improved productivity growth and there are some reasons to expect improvements to occurparticularly evidence of changes underway in the service sector. I look forward to finding out over the next several years what these changes really amount to.

\section{General Discussion}

Part of the discussion focused on whether the end-of-expansion effect identified by Robert Gordon was caused by firms' overhiring of labor. James Tobin proposed a model that would yield similar effects but did not rely on theories of overhiring. In this model, firms operate below the production function during downturns in the business cycle. After the trough, output may increase without corresponding increases in labor input. The higher productivity achieved could be seen as firms' returning to the production frontier, and not as the aftermath of overhiring. In a related vein, Tobin noted that the last expansion had peaked in the first quarter of 1989 on a GNP-gap basis, so that firms have had a long time in which to shed labor. By now, it is unlikely that much excess labor would remain. Consequently, a productivity surprise now was more likely to reflect a change in the level or trend of productivity, rather than a purely cyclical upswing.

Other participants accepted the descriptive hypothesis of overhiring 
advanced by Gordon, but asked for a better explanation of it. Henry Aaron suggested a need for a model of expectations formation by firms to explain the overhiring phenomenon. Christopher Carroll proposed that overhiring at the end of expansionary periods was not necessarily irrational because firms are not able to identify the start of recessions accurately. He pointed to $1966-67$ and $1985-86$ as examples of periods when recessions did not develop after periods of slowing growth. While Robert Hall felt that this was a side issue to the subject of the paper, he proposed that one could test for irrationality based on published or econometric forecasts. Gordon replied that he remained neutral on the issue of whether firms were rational or not in their hiring policies. However, he reported that his attempts to build an autoregressive forecasting model that replicated the end-of-expansion effect had been unsuccessful.

Both Robert Hall and Charles Schultze commented that it was too early to make any definitive statements about productivity trends after the last recession, despite evidence of an initial productivity surprise. Benjamin Friedman welcomed Gordon's cautioning against premature prophecies of new eras of productivity growth that have accompanied previous recoveries, such as in 1984. Daniel Sichel suggested examining measures of wages and prices as another way of testing whether a recent productivity surprise has occurred. However, Gordon pointed out that typically only 20 percent of a productivity improvement shows up as lower inflation; the rest results in higher profits. Hence a productivity surprise would not be readily detected in prices.

Gordon said that he put more weight than Martin Baily on the longrun view of productivity changes, which Baily dubbed the Nordhausdepletion view. According to this view, what is surprising is not the slow productivity growth in the last twenty years, but rather the exceptionally high growth between the 1920s and 1960s. Before this period, productivity growth rates were below those measured in recent years. Gordon also commented on the implication of the argument by J. Bradford De Long and Lawrence Summers in BPEA, 2:1992 that there is a large social return on equipment investment. Gordon pointed out that, if equipment were seen as the only type of capital that produces output, then calculations of multifactor productivity growth for the United States would show zero or negative growth. 


\section{References}

$\rightarrow$ David, Paul A. 1990. "The Dynamo and the Computer: An Historical Perspective on the Modern Productivity Paradox." American Economic Review, Papers and Proceedings 80(2):355-61.

Engle, Robert F., and C. W. J. Granger. 1987. "Co-Integration and Error Correction: Representation, Estimation, and Testing." Econometrica 55(2):25176.

Gordon, Robert J. 1979. "The 'End-of-Expansion' Phenomenon in Short-Run Productivity Behavior." BPEA, 2:1979, 447-61.

- 1982. "Inflation, Flexible Exchange Rates, and the Natural Rate of Unemployment." In Workers, Jobs, and Inflation, edited by Martin N. Baily. Washington: Brookings.

- 1992. "Are Procyclical Productivity Fluctuations a Figment of Measurement Error?" Working paper. Evanston, Ill.: Northwestern University (August).

. 1993. Macroeconomics, sixth edition. New York: Harper Collins.

Hendry, David F., Adrian R. Pagan, and J. Denis Sargan. 1984. "Dynamic Specification." In Handbook of Econometrics, vol. 2, edited by Zvi Griliches and Michael D. Intriligator. Amsterdam: North-Holland.

Hodrick, Robert J., and Prescott, Edward C. 1981. "Postwar U. S. Business Cycles: An Empirical Investigation.” Discussion Paper 451. Minneapolis, Minn.: University of Minnesota (May).

Hultgren, Thor. 1960. "Changes in Labor Cost during Cycles in Production and Business." Occasional Paper 74. New York: National Bureau of Economic Research.

Kydland, Finn E., and Edward C. Prescott. 1990. "Business Cycles: Real Facts and a Monetary Myth." Federal Reserve Bank of Minneapolis Quarterly Review. 14(2): 3-18.

Mishel, Lawrence, and Jared Bernstein. 1992. "Job Destruction: Worse Than We Thought." Challenge 35(5):4-8.

Okun, Arthur M. 1962. "The Gap between Actual and Potential Output," Proceedings of the American Statistical Association. Reprinted in Problems of the Modern Economy, edited by Edmund S. Phelps. New York: Norton, 1966.

Prescott, Edward C. 1986. "Theory Ahead of Business Cycle Measurement." In Real Business Cycles, Real Exchange Rates and Actual Policies, edited by Karl Brunner and Allan H. Meltzer. Carnegie-Rochester Conference Series on Public Policy 25.

Ritter, Joseph A. 1993. “The Delayed Recovery of Employment." National Economic Trends, Federal Reserve Bank of St. Louis (February):1.

Sims, Christopher A. 1974. "Output and Labor Input in Manufacturing." BPEA, 3:1974, 695-728.

Young, Allan H. 1992. "Alternative Measures of Change in Real Output and Prices." Survey of Current Business 72(4):32-48. 